\title{
Tipos de hábitat: definiciones y desafíos para su medición a partir del caso de la aglomeración Gran Buenos Aires
}

\author{
Habitat types: definitions and challenges for their measurement \\ based on the case of Greater Buenos Aires
}

\author{
Mariana Marcos \\ Instituto de Investigaciones Gino Germani, Universidad de Buenos Aires, \\ Consejo Nacional de Investigaciones Cientificas y Técnicas, Argentina
}

Resumen

El artículo se inserta en el campo de estudio de los tipos de hábitat (o tipos de poblamiento). A pesar de que estos entornos constituyen escenarios sociodemográficos con gran potencial diferenciador en las grandes aglomeraciones urbanas de América Latina, el uso de la perspectiva no se encuentra muy extendido. Aquí se abordan los desafíos para arribar a definiciones operacionales adaptadas a las especificidades de una ciudad y los condicionamientos derivados de la disponibilidad de datos. A partir del caso de Buenos Aires, se busca contribuir en dos niveles: en el más general, se aporta a las bases metodológico-conceptuales y a las condiciones de replicabilidad en otros contextos geográficos y temporales; y en el nivel del caso de Buenos Aires, se realiza la primera clasificación de su territorio en tipos de hábitat.

Palabras clave: Tipos de hábitat, metodología, metrópolis, Buenos Aires.

Abstract

This paper extends the existing approach to habitat types (or settlement types). Although these environments are sociodemographic scenarios with great differentiating potential in large urban agglomerations of Latin America, the use of the perspective is not widespread. This work addresses the challenges to reach operational definitions adapted to a concrete case and the constraints derived from data availability. Through the analysis of the case of Buenos Aires, we seek to contribute on two levels: in the most general, we provide evidence to broaden methodological and conceptual framework, and conditions of replicability in other geographical and temporal contexts; and at the level of the case of Buenos Aires, the first classification of its territory into habitat types is carried out.

Key words: habitat types, methodology, metropolis, Buenos Aires. 


\section{INTRODUCCIÓN}

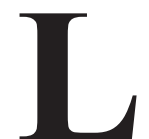

as ciudades, como cualquier otro fenómeno de la realidad social, resultan siempre sumamente complejas de abordar y aprehender en toda su extensividad y profundidad. En particular las grandes metrópolis se nos presentan inabarcables y desde las ciencias sociales hemos necesitado desagregarlas: desarmarlas verticalmente fraccionándolas en partes y descomponerlas horizontalmente distinguiendo capas, a menudo estudiadas por diferentes áreas del conocimiento y disciplinas científicas.

Con décadas de desarrollo de estos procesos de generación de conocimiento a nuestras espaldas, hemos logrado niveles de especialización disciplinar y profesional tales, que paradójicamente la cuenta pendiente suele ser recomponer el todo - en este caso, la ciudad — en particular cuando se trata de generar conocimiento con fuerte anclaje en datos empíricos.

En este trabajo se reconoce al concepto de "tipo de hábitat" (o "tipo de poblamiento") como herramienta teórica valiosa para el estudio de grandes ciudades, precisamente por su ductilidad para abarcar la totalidad de su territorio e integrar diversos aspectos de su realidad, que con frecuencia aparecen abordados por separado y desde distintas disciplinas. Los tipos de hábitat constituyen entornos urbanos con dinámicas poblacionales, sociodemográficas y residenciales específicas que se pueden identificar en la ciudad considerando el momento y las condiciones históricas en las que se desarrolló el poblamiento de diferentes áreas y la forma en la que se produjo el espacio habitacional (Connolly, 2005). En términos operativos, como tipos de hábitat de la ciudad se pueden reconocer el primer núcleo urbano y su expansión temprana, las zonas que en el pasado fueron poblados independientes y las urbanizaciones que responden a distintas modalidades de producción de ciudad, como la promoción pública de vivienda, la ocupación informal del suelo, el parcelamiento del antiguo suelo rural en lotes con apego a la normativa vigente y los grandes desarrollos habitacionales privados.

En los tipos de hábitat confluyen los análisis de la demografía espacial y la geografía urbana, que han documentado la heterogeneidad funcional y social interna de las ciudades y su evolución como parte constitutiva de los sistemas de asentamiento nacionales (el avance de las ciudades y pueblos sobre el campo abierto y la eventual coalescencia entre ellos, y el proceso de densificación de las áreas urbanas en el marco de la urbanización de los países); y los análisis de la sociología urbana acerca del modo de pro- 
ducción del espacio urbano en diferentes contextos espaciales, temporales, demográficos y normativos, a los que están fuertemente supeditadas las posibilidades y condiciones de acceso a la ciudad de los actores sociales.

En este artículo se abordan los desafíos metodológicos para la medición del concepto en América Latina, a partir de la descripción pormenorizada de una experiencia de aplicación al caso de Buenos Aires. Con ello se pretende impulsar los estudios en este campo por una doble vía: por un lado, generando condiciones de replicabilidad en otros contextos geográficos y temporales; $y$, por otro, demostrando los promisorios y siempre vigentes resultados que se pueden obtener, en convergencia con los aportes previos sobre el área metropolitana de México y avances — hasta ahora inconclusos- sobre el caso de Buenos Aires.

\section{EL CONCEPTO DE "TIPOS DE HÁBITAT" Y LOS ANTECEDENTES SOBRE Buenos Aires}

El concepto de "tipos de hábitat" puede situarse en la línea de trabajos preocupados por las desigualdades socio-espaciales intraurbanas, que tiene una extensa trayectoria en el campo de las ciencias sociales. Los estudios pioneros fueron llevados adelante hacia principios del siglo XX por la Escuela de Chicago de Sociología, motivados por la preocupación por la creciente presencia de migrantes en las ciudades y las causas y consecuencias de sus particulares patrones de asentamiento. Uno de los pilares teóricos de la Escuela de Chicago fue la categoría de "segregación", que posteriormente trascendió a los estudios migratorios para adquirir diferentes "apellidos" de acuerdo a los atributos que definen a los grupos sociales distribuidos en la ciudad de modo tal que tienden a conformar áreas urbanas homogéneas en su interior y heterogéneas entre sí (Rodríguez Vignoli, 2001). En el plano metodológico, sentó las bases para el desarrollo de la ecología factorial, que en su versión exploratoria permitió identificar dimensiones latentes en la información censal y superar el problema del gran volumen que ésta adquiere al ser desagregada a nivel unidades geoestadísticas urbanas pequeñas. Y como herramienta que permitió construir postulados teóricos a partir de los resultados de base empírica, deben destacarse las modelizaciones de la ciudad, que reconocen espacios definidos por los usos del suelo y el nivel socioeconómico de la población que se asienta en ellos.

Si bien la Escuela de Chicago recibió fuertes cuestionamientos desde la geografía crítica y la nueva sociología urbana (Lefebvre, 1972; Castells, 1977; Harvey, 1998, entre otros), el camino iniciado, lejos de verse clausurado, se ramificó en múltiples sentidos — con puntos de contacto y también 
disidencias entre las vías alternativas-, y tiene continuidad hasta la actualidad, funcionando como piedra fundacional de lo que es una extensa línea de estudios y debates con identidad y agenda propias.

La perspectiva de los tipos de hábitat, conocida también como "tipos de poblamiento", es un hito en ese extenso y sinuoso devenir. Surgió en México a finales de la década de 1970 (COPEVI, 1978) como un recurso teórico de bajo nivel de abstracción impulsado desde la geo-demografía para identificar contextos urbanos que dieran cuenta de los diferenciales espaciales que se pueden encontrar tanto en la estructura y la dinámica demográfica de la población, como en sus condiciones de vida.

El punto de partida de los trabajos mexicanos es la premisa de que "la división social del espacio residencial responde en sus grandes tendencias a las formas de producción del espacio habitacional coexistentes en la ciudad y a su evolución a lo largo del tiempo" (Duhau y Giglia, 2008: 269); y de ello se desprende que ellas deben ser tenidas en cuenta al clasificar el territorio urbano si se pretende revelar las "interrelaciones entre el hábitat y las características socio-demográficas de la población" (Connolly, 2005: 3).

Según Priscilla Connolly -quien tuvo participación en estos estudios desde los inicios-, "el tipo de poblamiento se refiere fundamentalmente al origen de la urbanización de un área determinada de la ciudad, diferenciado por dos criterios básicos: i) fecha de urbanización y ii) forma de producción del espacio habitacional. La forma de producción del espacio habitacional es un concepto que conjuga la condición legal original del asentamiento, los principales agentes sociales involucrados en la urbanización y en la producción de vivienda, la duración de los procesos de construcción y los rangos de precios de acceso consiguientes" (Connolly, 2005: 2). En la zona metropolitana de México, a partir del criterio de la fecha de urbanización se distinguen como tipos de poblamiento el área fundacional o casco histórico (ciudad colonial), su primera expansión que en la actualidad cumple la función de centro (ciudad central) y las superficies que se corresponden con antiguos poblados que hoy se han conurbado (cabeceras y pueblos conurbados) o permanecen escindidos espacialmente de la aglomeración principal (pueblos no conurbados); y a ello se agregan los tipos de poblamiento que se derivan de la forma de producción del espacio habitacional, como los conjuntos de vivienda social promovidos por el Estado (conjuntos habitacionales), las áreas residenciales de origen informal (colonias populares) y las áreas residenciales de origen formal derivadas de la progresiva expansión de la planta urbana mediante el fraccionamiento de suelo rural circundante en parcelas de uso residencial urbano, que por 
distintos motivos - fundamentalmente, el funcionamiento del mercado inmobiliario - han alcanzado diferentes niveles de consolidación (residencial medio y alto).

De este modo, la clasificación que se realiza del territorio de la ciudad y sus proximidades tiene en cuenta la conformación de áreas de composición socioeconómica diferencial - lo cual puede considerarse un punto de contacto teórico-metodológico con las perspectivas de la segregación residencial socioeconómica y los mapas sociales-, pero atendiendo al objetivo específico de lograr una tipología funcional que dé cuenta de diferentes estructuras y dinámicas demográficas de la población, incorpora otras dimensiones constitutivas del espacio habitacional con las que ellas están relacionadas.

Si en la conceptualización mexicana se utiliza el término "tipos de poblamiento" - $\mathrm{y}$ con ello se pone el acento en la producción de ciudad como proceso que fue dando lugar a distintos entornos residenciales-, aquí se utiliza, en cambio, "tipo de hábitat", corriendo el foco al espacio-resultado o espacio como producto social (Lefebvre, 1972), para dar continuidad a una línea de trabajo personal acerca de la dimensión sociológica del espacio en Buenos Aires y completarla con la dimensión material.

Hasta el momento, el espacio residencial construido que conforma la Aglomeración Gran Buenos Aires (AGBA) no se había abordado en su totalidad desde la perspectiva de los tipos de hábitat, aunque existe un vasto corpus de trabajos que deben reconocerse como antecedentes.

Por un lado, desde perspectivas teóricas distintas a la de tipos de hábitat, se han producido importantes resultados empíricos acerca de la AGBA que, reunidos y reinterpretados en esta nueva clave, constituyen valiosos antecedentes que allanan el camino hacia la identificación de entornos urbanos en la ciudad. Entre ellos se destacan los estudios de la estructura socio-espacial metropolitana desde perspectivas como los mapas sociales desde los trabajos pioneros de Horacio Torres $(1978 ; 1993 ; 2001)$ hasta los más recientes de María Eugenia Goicoechea y Artemio Abba (2020)—, los mapas sociales urbanos (Buzai y Marcos, 2012), la segregación residencial socioeconómica (Groisman y Suárez, 2009; Rodríguez, 2016; Vergara Parra, 2018a) y la demografía urbana (Marcos, 2015). En un segundo grupo de antecedentes pueden incluirse aquellos abordajes cuantitativos enfocados en alguna tipología de hábitat en particular, como las urbanizaciones de origen informal (Del Río et al., 2008; Cravino et al., 2010; Vergara Parra, 2018b; Dadamia, 2019), los conjuntos habitacionales (Dunowicz y Rey, 2000; Dunowicz y Boselli, 2009; Bekinschtein et al., 2013; Di Virgi- 
lio et al., 2017) y las urbanizaciones cerradas (Janoschka, 2002; Thuillier, 2005; Vidal-Koppmann, 2008; Borsdorf et al., 2016). Finalmente, también hay autores que han documentado el proceso de poblamiento de parte o la totalidad de la actual superficie de la ciudad (Vapñarsky, 2000; Rodriguez y Kozak, 2014).

Por otro lado, existen estudios sobre Buenos Aires que pueden situarse teóricamente en la perspectiva de los tipos de hábitat o sus proximidades. Juan Pablo del Río (2012), preocupado por el mercado del suelo más que por la dimensión habitacional de las desigualdades metropolitanas, en su tesis doctoral incluyó una clasificación de la estructura urbana del conurbano bonaerense según las condiciones del mercado de localización residencial, teniendo en cuenta la calidad urbana (el acondicionamiento y cualificación del espacio urbano), el nivel socioeconómico y la distancia del borde urbano. Tres años más tarde salieron a la luz una serie de estudios de Mercedes Di Virgilio, Mariana Marcos y Gabriela Mera (Marcos et al., 2015; Mera et al., 2015; Di Virgilio et al., 2015; 2016) en los que ensayaron una primera aplicación del concepto de tipos de hábitat en la Argentina, aunque circunscripta a la Ciudad Autónoma de Buenos Aires (CABA). Este artículo se sitúa a continuación, y sistematiza las principales decisiones metodológico-conceptuales involucradas en la revisión de la primera clasificación de la CABA y en la clasificación de su vasta conurbación, que hasta ahora había constituido una importante cuenta pendiente.

\section{LOS DESAFÍOS EN EL RECORRIDO DE LOS CONCEPTOS A SU MEDICIÓN}

La identificación de los tipos de hábitat de una ciudad requiere de materiales como cartografía histórica del área y registros georreferenciados de urbanizaciones de diferente condición de regularidad elaborados por distintos actores. En una etapa posterior, el estudio de los atributos de los tipos de hábitat identificados se realiza en base a datos del censo de población, que es la única fuente que proporciona información para unidades espaciales pequeñas a partir de las que se pueden reconstruir — con cierto margen de error - superficies intraurbanas ad-hoc. Debido a esto último, es conveniente que las distintas fuentes correspondan a fechas próximas al censo con el que luego se caracterizará a los tipos de hábitat identificados.

La búsqueda y recopilación de datos secundarios y su evaluación y puesta a punto para su utilización integrada es una actividad ardua, que puede deparar numerosos obstáculos e imprevistos que la prolonguen en el tiempo más allá de lo planeado y hasta supongan reconceptualizaciones de distinta envergadura, en el sentido de que la definición de algunos tipos 
de hábitat deberá adaptarse a lo posible. Dada la multiplicidad de fuentes que se requieren y el hecho de que la mayoría de ellas no son producidas de forma centralizada y estandarizada por organismos del sistema estadístico de un país, muy probablemente se hallen comprometidas cuestiones como la adecuación geográfica, temporal y conceptual de los datos secundarios, su calidad y su compatibilidad técnica (soporte analógico/ digital; georreferenciado/ no georreferenciado; sistema de coordenadas utilizado; etcétera). Más aún en el caso de grandes ciudades latinoamericanas bajo la órbita de varias administraciones de segundo orden y de orden local (en el caso de Buenos Aires, dos provincias y treinta y dos municipios), en cuyas dependencias se suele descentralizar la producción de información para la gestión.

Una vez que se dispone de las fuentes necesarias para construir el mosaico de tipos de hábitat que conforman la ciudad, un segundo desafío es "buscar" los tipos de hábitat en la cartografía censal para poder conocer sus atributos sociodemográficos a partir de la información relevada por el censo. Ello supone afrontar el denominado "problema de la unidad espacial modificable" (PUEM) (Openshaw, 1977). Es frecuente que aún las unidades geoestadísticas más pequeñas para las que se publica información censal sean muy grandes para reconstruir con precisión las fronteras entre un tipo de hábitat y otro, ante lo cual necesariamente se debe recurrir a paliativos para darle tratamiento al problema (pero difícilmente solución, puesto que la desagregación espacial de la información encuentra en las unidades geoestadísticas censales de menor tamaño un umbral infranqueable).

Con tan sólo superponer la cartografía censal con imágenes satelitales y con la cartografía de los tipos de hábitat, es habitual que se observe que no se pueden reconstruir con exactitud ni la aglomeración (el universo de análisis) ni los tipos de hábitat que hay en su interior, agregando las unidades geoestadísticas censales - aun tratándose de las más pequeñas disponibles-.

Existen gran cantidad de propuestas de distinto nivel de complejidad para afrontar el PUEM, pero no hay consenso en cuanto a en qué medida logran mitigar su efecto (Wong, 2009). Para dirimir la clasificación de las unidades geoestadísticas mixtas (de composición heterogénea), los trabajos antecedentes sobre la Ciudad de México y la CABA consideraron el tipo de hábitat preponderante. Los trabajos mexicanos establecieron esta preponderancia fundamentalmente en base al porcentaje de superficie de las unidades geoestadísticas que abarca cada tipo de hábitat. Para el caso de Buenos Aires las autoras realizaron el esfuerzo adicional de tener en 
cuenta múltiples criterios, incluyendo a la superficie de uso residencial que abarca cada tipo de hábitat, pero también su densidad relativa, que exploraron mediante fotointerpretación de imágenes satelitales próximas a la fecha del censo y consulta de datos censales correspondientes al tipo de viviendas y —eventualmente - su condición de ocupación.

La caracterización posterior de los tipos de hábitat en base a los datos censales también se ve condicionada por las posibilidades y limitaciones de la fuente. Al hecho de que el diseño de las unidades geoestadísticas pequeñas de los censos no responde al objetivo de dar cuenta de la heterogeneidad de la población que se asienta en el territorio, se suelen agregar otros problemas, como la redefinición de la superficie, la forma y la codificación de las unidades geoestadísticas a lo largo del tiempo, el relevamiento de parte de la información a través de muestras representativas de unidades político-administrativas mayores para abaratar costos y la agregación espacial de la información en etapas de codificación o publicación de los datos. Todo ello se traduce en importantes condicionamientos a tener en cuenta al estudiar los tipos de hábitat en un momento dado y aún más al comparar su cambio en el tiempo.

\section{El caso de la Buenos Aires metropolitana}

La AGBA es la mancha urbana o asentamiento humano que se recorta en campo abierto (Figura 1), identificada operacionalmente a partir de la presencia de elementos físicos como calles, edificios y manzanas - de acuerdo a las especificaciones del Instituto Nacional de Estadística y Censos (INDEC) - (Vapñarsky, 1998). Al momento del último censo de población argentino de 2010, la ciudad tenía aproximadamente 246 mil hectáreas (Rodríguez y Kozak, 2014) en las que se empadronaron 13'588,171 personas. Sólo algo más de 20 mil hectáreas y menos de tres millones de personas (ocho por ciento de la superficie y 20 por ciento de la población) corresponden a la entidad político administrativa que lleva el nombre de (Ciudad Autónoma de) "Buenos Aires". El resto constituye la amplia conurbación de ese núcleo central, que adoptó forma tentacular al estructurarse en torno a las principales vías de comunicación. 
Tipos de hábitat: definiciones y desafíos para su medición a partir del caso de la aglomeración Gran Buenos Aires / M. MARCOS

Figura 1: Aglomeración Gran Buenos Aires en 2010

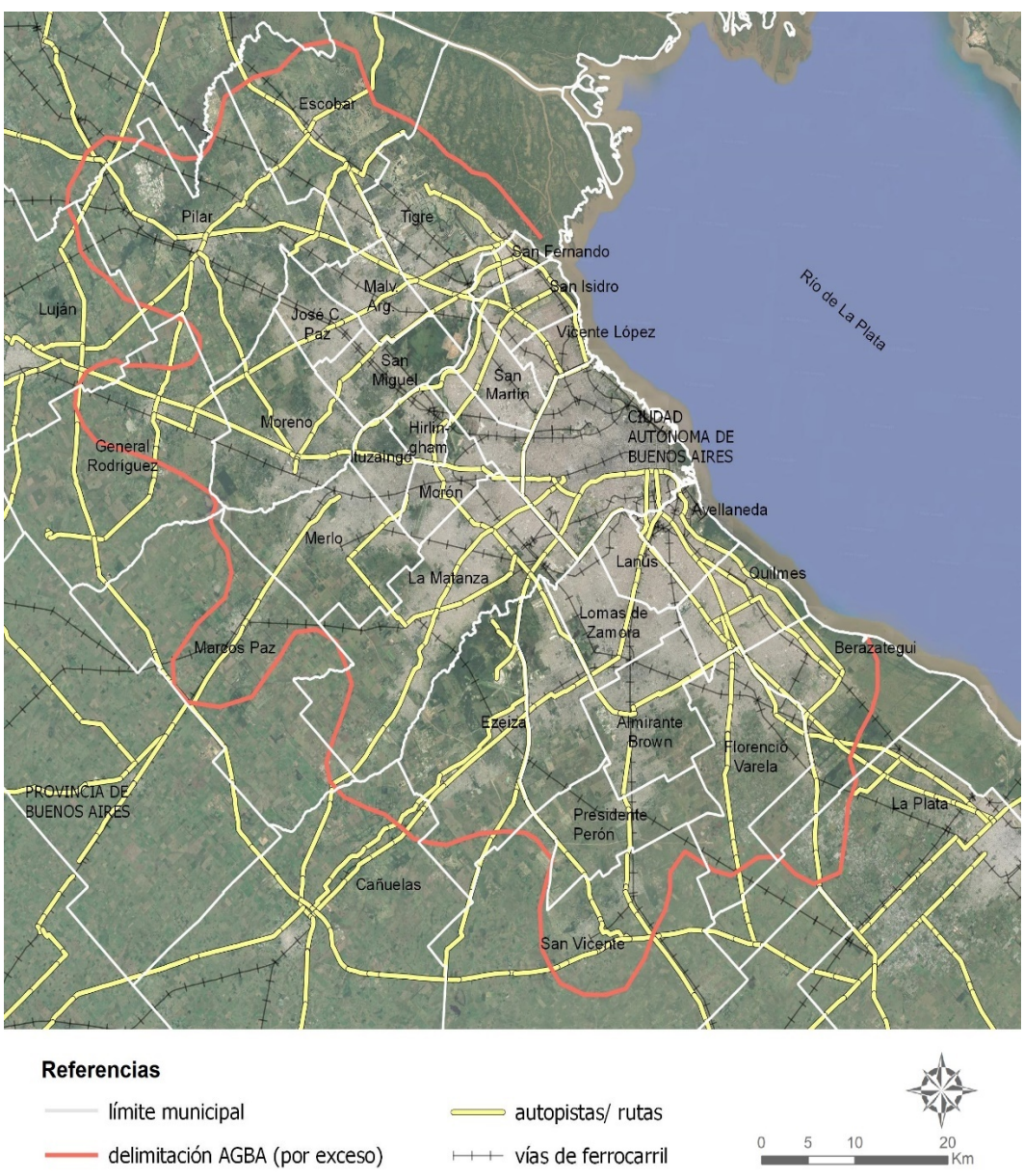

Fuente: elaboración con base en imágenes satelitales de Google Earth; cartografía del Instituto Geográfico Nacional; y Rodríguez y Kozak, 2014. 
A pesar de que las imágenes satelitales revelan la compacidad de la ciudad así definida, su administración se encuentra descentralizada en dos provincias (entidades político-administrativas de segundo orden) y más de una treintena de municipios (entidades político-administrativas de orden local), entre los que se pueden encontrar grandes diferencias de recursos - humanos y presupuestarios - y orientaciones políticas, con el agravante de que no se hallan coordinados por una autoridad metropolitana. Esta situación se comprende a la luz de, por un lado, el proceso de poblamiento del área actualmente abarcada por la ciudad, que involucró la expansión del núcleo urbano inicial, pero también la progresiva anexión de núcleos urbanos independientes que tenían - y conservaron - su propia administración local; y, por el otro, de la subdivisión de antiguos municipios para contar con administraciones locales en áreas que fueron creciendo en cantidad de población y complejidad.

Tras la aparente homogeneidad que muestra la imagen satelital también se oculta la estratificación socio-espacial de Buenos Aires. Los estudios pioneros que dieron cuenta de este fenómeno en la AGBA datan de mediados de la década de 1970, cuando Horacio Torres publicó sus primeros "mapas sociales" (Torres, 1978). A ello siguieron numerosos esfuerzos de actualización y complejización de estos primeros trabajos (entre ellos, Torres, 2001; Groisman y Suárez, 2009; Buzai y Marcos, 2012; Marcos, 2015; Rodríguez, 2016; Goicoechea y Abba, 2020).

En la actualidad la ciudad se estructura en un área de nivel socioeconómico alto o muy alto conformada por el centro y norte de la CABA, los municipios costeros del norte (Vicente López y San Isidro) y las zonas centrales de los demás municipios, localizadas a lo largo de las vías de comunicación ferroviarias que dinamizaron el crecimiento de la ciudad durante la etapa industrial (1930-1970). Desde este núcleo y sus ramificaciones radiales, el nivel socioeconómico se degrada progresivamente hacia la periferia, de modo que las áreas de nivel socioeconómico intermedio son la antesala de las áreas más degradadas y peor comunicadas, por tratarse de zonas periféricas o intersticiales. Los bolsones de pobreza y de riqueza asociados, respectivamente, a urbanizaciones informales y cerradas, constituyen una importante excepción a este patrón, en tanto algunas de las primeras - las que sobrevivieron a los intentos de erradicación de la última dictadura (1976-1983) — se encuentran localizadas dentro de la CABA; y los segundos —en donde se asentaron familias de mayores recursos desde fines del siglo XX - se localizan en la periferia de la ciudad, irrumpiendo 
en los contextos que tradicionalmente habían estado reservados para los sectores populares.

La estructura actual de la AGBA cristaliza así, como capas superpuestas de su historia, las huellas de diferentes procesos que las fotos estáticas de la ciudad no revelan por sí mismas. Los tipos de hábitat vienen a echar algo de luz sobre el modo en que se conformó este mosaico de entornos habitacionales, que por momentos hace pensar en una multiplicidad de "ciudades dentro de la ciudad" (Di Virgilio, Marcos y Mera, 2015), con sus poblaciones particulares.

Teniendo como punto de partida la definición nominal de "tipos de hábitat", la definición operacional de cada uno de ellos puede variar de una ciudad a la otra de acuerdo con la especificidad de los procesos históricos de su conformación y la estructura interna resultante. A ello se agregan las reconceptualizaciones involuntarias de facto a las que hay que resignarse, por los condicionamientos que imponen los datos secundarios.

En el caso de Buenos Aires, a partir del criterio del periodo de poblamiento, se distinguieron tres categorías: la ciudad colonial, la expansión de la ciudad colonial y los cascos conurbados.

1. Ciudad Colonial: corresponde aproximadamente a la ciudad de Buenos Aires a finales de la Colonia (Figura 2). En el actual territorio de Argentina el proceso que llevó al fin de la etapa colonial reconoce su inicio en la Revolución de Mayo del año 1810 y tiene su punto culminante seis años después, con la declaración de la independencia del 9 de julio de 1816. Por disponibilidad de datos, en términos operacionales la ciudad colonial se definió como la aglomeración del año 1800 (Vapñarsky, 2000). Ello se ajusta mejor a la definición teórica de este tipo de hábitat que el área de protección histórica considerada por Marcos, Di Virgilio y Mera (2015), puesto que esta última remite al patrimonio urbano colonial y poscolonial que se intenta preservar en la actualidad.

2. Expansión de la ciudad colonial: corresponde a la expansión inicial de la ciudad colonial hacia finales del siglo XIX (1895 en la Figura $3)$, cuando el núcleo colonial ya había comenzado a avanzar sobre el campo abierto circundante, pero no había traspasado el actual límite de la CABA - a excepción de algunas zonas del municipio de Avellane$\mathrm{da}$ - Dado su temprano poblamiento, esta superficie tiene la suficiente antigüedad como para haberse consolidado en términos urbanísticos, pero ello no ocurrió de forma homogénea, pudiéndose encontrar diversidad de edificaciones, usos del suelo y perfil socioeconómico de 
sus ocupantes. En el antecedente de Marcos, Di Virgilio y Mera (2015) este tipo de hábitat se homologó al centro administrativo y de negocios, pero ello remite al uso actual del suelo de ese sector de la ciudad, más que al proceso de poblamiento.

3. Cascos urbanos: asentamientos urbanos o pueblos que se encontraban separados del área urbanizada continua de la AGBA en el pasado y que posteriormente fueron absorbidos por ella (Figura 3). En la actualidad se caracterizan por sus elevados niveles de consolidación urbana y muchos de ellos constituyen subcentralidades o cabeceras municipales. Dado que Buenos Aires fue avanzando paulatinamente sobre antiguos pueblos, se distinguieron cohortes de cascos urbanos definidas por el período en que se conurbaron con la AGBA, según los datos históricos disponibles: i) cascos existentes en 1895 que se conurbaron entre ese año y 1910; ii) cascos existentes en 1910 que se conurbaron entre ese año y 1948; y iii) cascos existentes en 1948 que se conurbaron después de ese año. Así, las superficies de los cascos conurbados corresponden a diferentes momentos $(1895,1910$ y 1948), pero recibieron tratamiento conjunto como un único tipo de hábitat.

El resto de la AGBA se clasificó de acuerdo al modo de producción que dio origen a cada área de la ciudad (la regularidad inicial de la tenencia del suelo y los agentes que protagonizaron la urbanización en cada caso). Se distinguieron urbanizaciones de origen informal, conjuntos habitacionales de vivienda social, urbanizaciones cerradas y fraccionamientos por loteo formal de distinto nivel socioeconómico.

4. Urbanizaciones de origen informal (en rojo en la Figura 4): resultan del poblamiento de tierras degradadas protagonizado por sectores populares cuya característica distintiva es la informalidad en la tenencia del suelo (la ausencia de títulos de propiedad y el carácter no autorizado del poblamiento del área), que suele ir acompañada de escases de infraestructura y servicios urbanos y de predominio de viviendas de autoconstrucción sin apoyo de planos o de viviendas prefabricadas de baja calidad. Dentro de esta categoría se pueden distinguir subtipos de acuerdo a la regularidad y densidad de la trama urbana, la amplitud de las vías de circulación, la dotación de espacio verde, el nivel de organización de los hogares para la ocupación del predio y legitimarse como sus propietarios, y el nivel de firmeza de las viviendas. En el caso de Buenos Aires, se recurrió a registros de urbanizaciones de origen informal de la CABA (DGEyC, s/f) y de la Provincia de Buenos Aires (RPPVA, 2015), que primero debieron armonizarse, para luego 
seleccionar las categorías afines al concepto de "urbanización de origen informal" que se utiliza aquí.

5. Urbanizaciones cerradas (en verde en la Figura 4): emprendimientos urbanísticos perimetrados y de acceso restringido, promovidos por grandes desarrolladores privados en áreas suburbanas bien conectadas con el centro de la ciudad, cuyas viviendas —en su mayoría unifamiliares y de gran tamaño- son residencia principal o secundaria de hogares de ingresos medio-altos y altos. El tamaño de los lotes y la infraestructura de uso común de los residentes pueden diferir en gran medida de acuerdo al subtipo de urbanización cerrada y al sector social al que estén destinadas. Su surgimiento en Buenos Aires tiene antecedente en los barrios de casas de fin de semana o casaquintas concebidos desde su creación como cerrados, pero su proliferación y utilización como lugar de residencia principal data de las últimas décadas. Ello fue registrado por la Provincia de Buenos Aires (urBAsig, $\mathrm{s} / \mathrm{f}$ ) —aunque sin datos públicos imprescindibles como definiciones operacionales y criterios de empadronamiento-y debió completarse mediante fotointerpretación, dado que se detectaron omisiones.

6. Conjuntos habitacionales de vivienda social (en violeta en la Figura 4): conjuntos de viviendas multifamiliares (departamentos) o unifamiliares (casas en pequeños terrenos independientes o en dúplex) construidas en serie y en cantidad predeterminada, y financiadas total o parcialmente por el sector público. Los espacios resultantes pueden ser de distinto tamaño y densidad y en general se caracterizan por su homogeneidad interna y por tener infraestructuras urbanas previstas en el diseño. La información relativa a ellos se encuentra centralizada y sistematizada en el caso de la CABA, pero no así en la Provincia de Buenos Aires, donde el Instituto de la Vivienda no cuenta con registros completos de calidad. Se detectaron tanto conjuntos habitacionales incluidos en registros que aún no se encontraban finalizados y ocupados por familias adjudicatarias en el año 2010 - momento de referencia de este trabajo-, como la existencia de conjuntos omitidos. Para dar solución a la primera situación se consultaron imágenes satelitales y datos censales correspondientes a las zonas en que se encuentran localizados los conjuntos. La recuperación de las omisiones, por su parte, se vio dificultada por las diversas modalidades y canales institucionales a través de los que se administran los fondos públicos destinados a vivienda social — que, a su vez, han ido cambiando en el tiempo-, lo cual condicionó la posibilidad recurrir a los organismos de promoción 
y dejó como mejor opción la fotointerpretación de imágenes satelitales.

7. Fraccionamientos por loteo formal: zonas residenciales que se originaron a partir del proceso de suburbanización de la ciudad en base a la subdivisión de suelo antes rural y la venta de los lotes o parcelas para uso habitacional en apego a la normativa correspondiente (que en Buenos Aires no siempre exigió infraestructura urbana completa previa). ${ }^{1}$ La vivienda es unifamiliar (en general de autopromoción - a través de la contratación de trabajadores de la construcción e inclusive de arquitectos - o de autoconstrucción, de acuerdo a las posibilidades de las familias) o en propiedad horizontal (construida por desarrolladores privados). Se pueden distinguir espacios relativamente homogéneos en su interior y heterogéneos entre sí según el nivel socioeconómico de los residentes, que suele estar correlacionado de forma positiva con el nivel de provisión de servicios e infraestructuras urbanas. En términos operativos, se trata de las áreas de la ciudad que no quedaron clasificadas en los tipos de hábitat previos y que son clasificadas en zonas de distinto nivel socioeconómico de acuerdo a los atributos de los hogares que residen en ellas, sus integrantes y sus viviendas.

Se distinguieron tres niveles socioeconómicos (alto, medio y bajo) recuperando la adaptación de la experiencia de México realizada para la CABA por Marcos, Mera y Di Virgilio (2015): en lugar de los indicadores utilizados en México por Duhau y Giglia (2008) (viviendas con agua entubada en su interior; viviendas con calentador de agua; viviendas con computadora; población de 18 años o más con instrucción superior; y población ocupada que obtiene más de cinco salarios mínimos), considerando las particularidades de Buenos Aires y la disponibilidad de información, se utilizaron dos indicadores de servicios básicos (hogares con agua de red pública dentro de la vivienda y hogares que utilizan como combustible para cocinar principalmente gas de red, gas a granel o gas en tubo), un indicador asociado con tecnologías cada vez más importantes pero no siempre disponibles (hogares con computadora) y un último indicador de nivel educativo usualmente correlacionado con el nivel de ingresos (población de 25 a 64 años con educación universitaria completa).

\footnotetext{
1 La Ley de Ordenamiento Territorial y Uso del Suelo de Buenos Aires (Decreto-Ley 8912/77) data de 1977 y estableció estándares de urbanización que restringieron la subdivisión de la tierra sin redes de infraestructura.
} 
Tipos de hábitat: definiciones y desafíos para su medición a partir del caso de la aglomeración Gran Buenos Aires / M. MARCOS

Figura 2: Aglomeración Gran Buenos Aires en 1800 y Área de protección histórica original de 1979

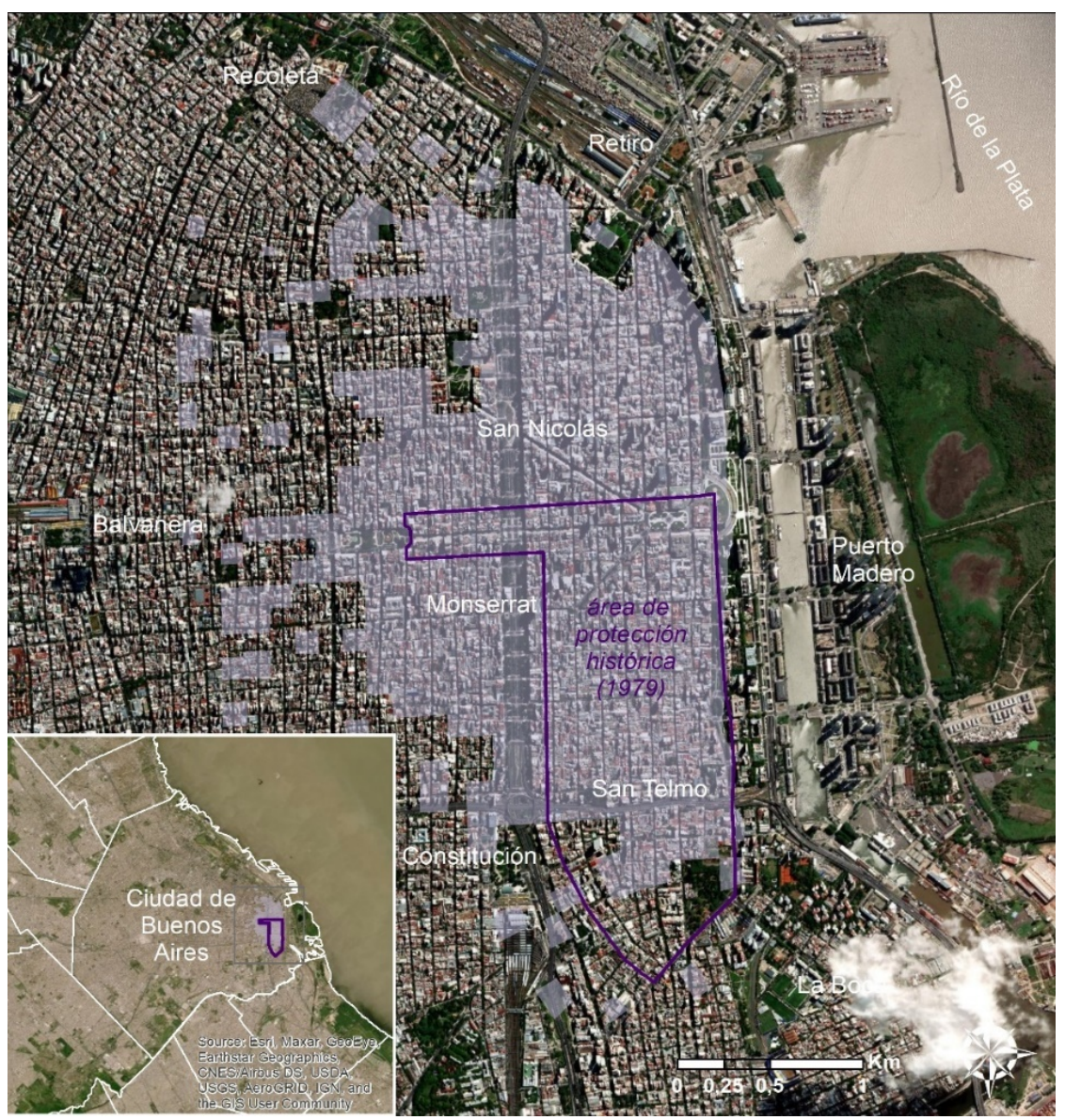

Fuente: elaboración con base en Vapñarsky, 2000 (digitalizado por Rodríguez y Kozak, 2014), Magadán, 2003 e imágenes de Google Earth. 
Figura 3: Cascos urbanos conurbados por cohorte

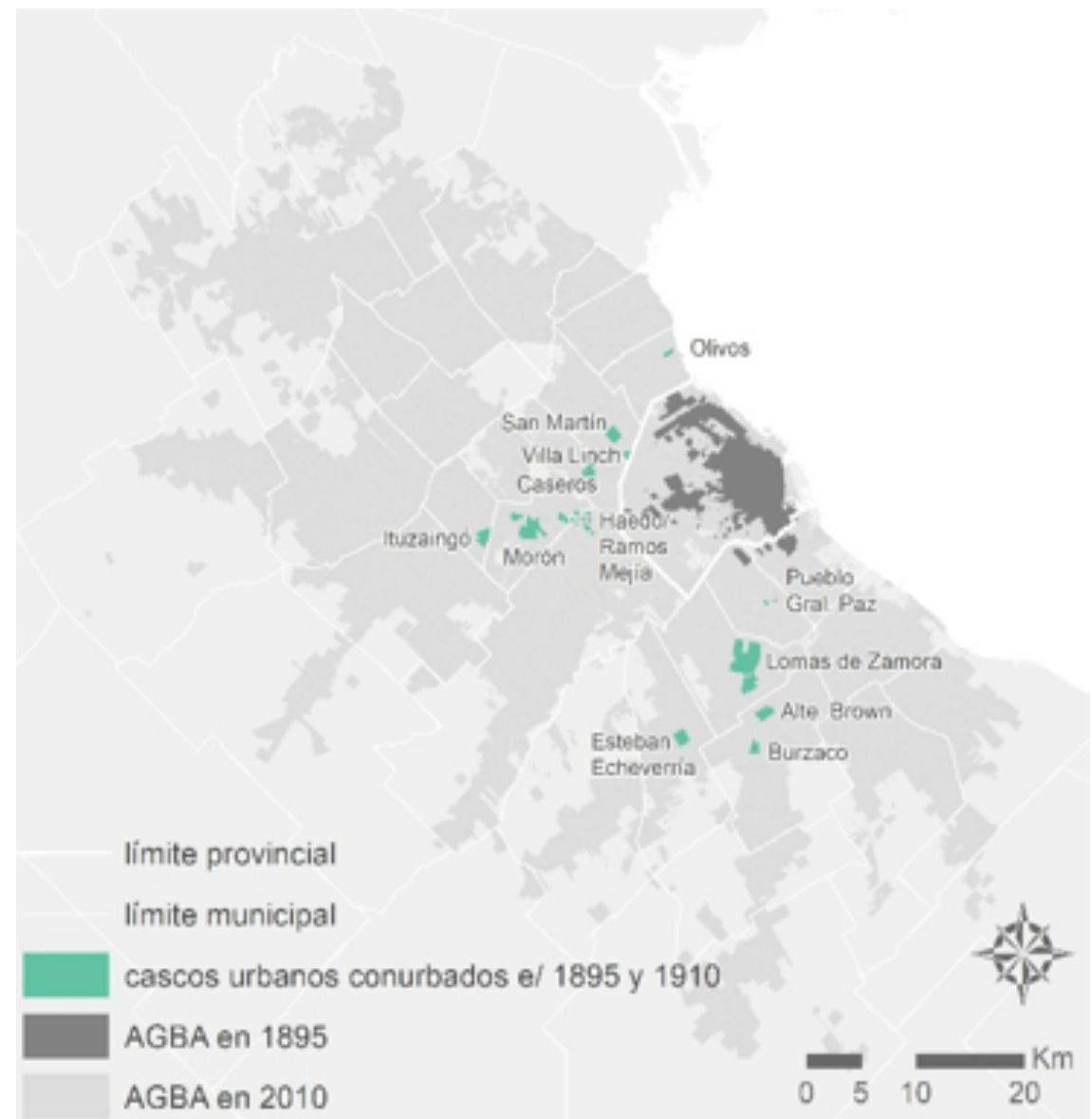

Fuente: elaboración con base en Vapñarsky, 2000, digitalizado por Rodríguez y Kozak (2014) y Nicolás Caloni. 
Tipos de hábitat: definiciones y desafíos para su medición a partir del caso de la aglomeración Gran Buenos Aires / M. MARCOS

Figura 3: Continuación

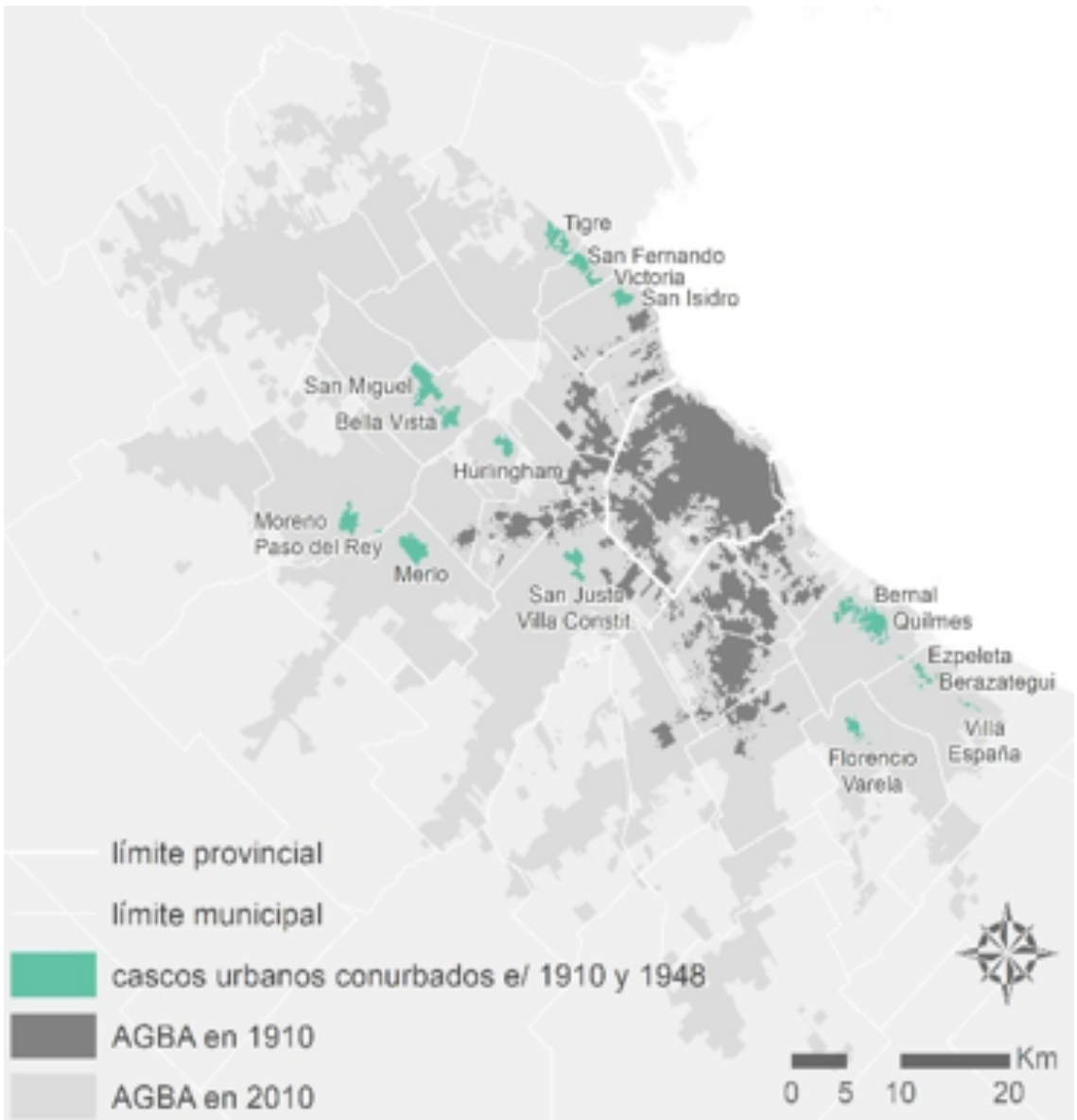

Fuente: elaboración con base en Vapñarsky, 2000, digitalizado por Rodríguez y Kozak (2014) y Nicolás Caloni. 
Figura 3: Continuación

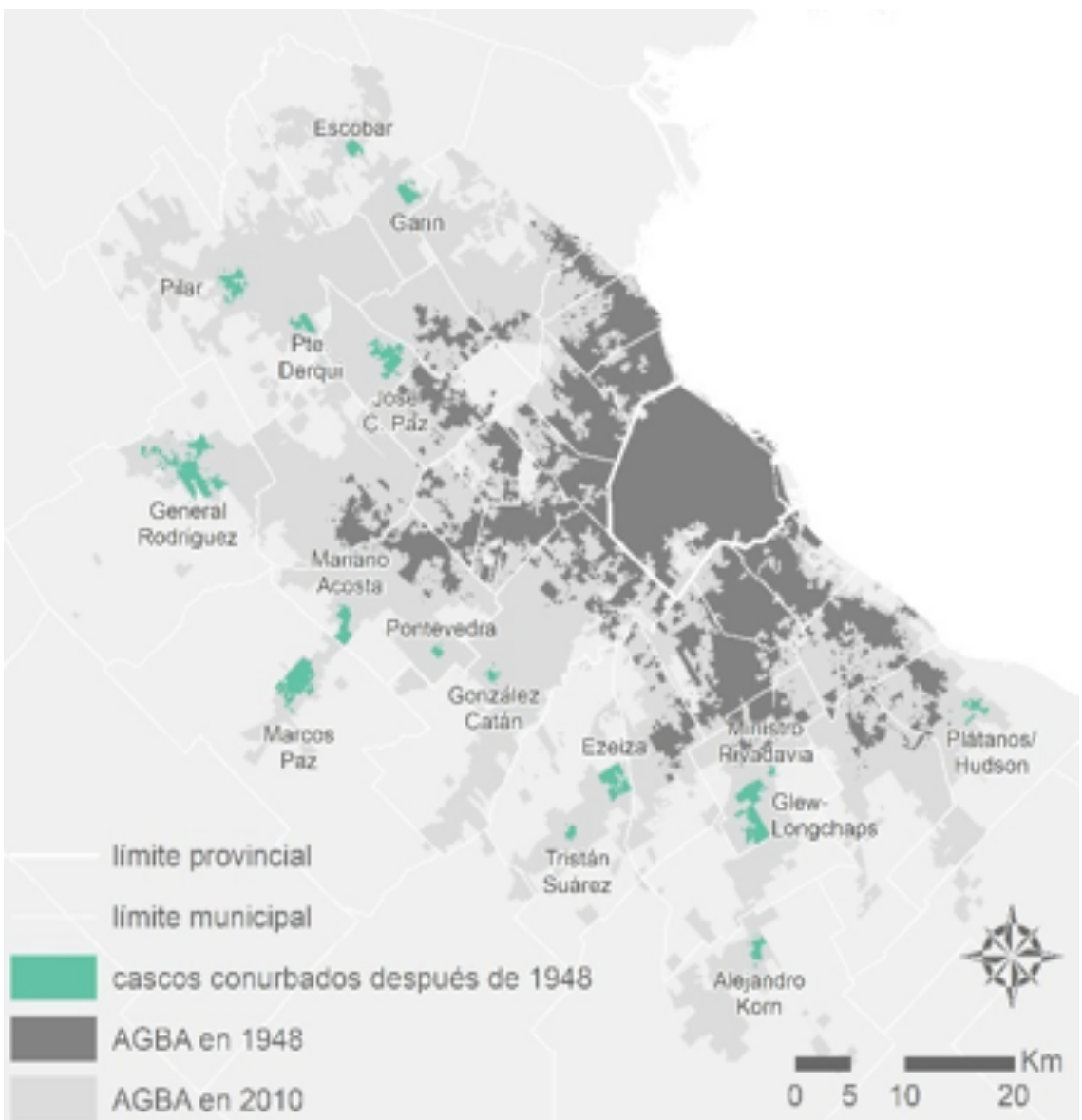

Fuente: elaboración con base en Vapñarsky, 2000, digitalizado por Rodríguez y Kozak (2014) y Nicolás Caloni.

También se siguió el criterio de las autoras de distinguir tres niveles socioeconómicos, incorporando un nivel "bajo" que no se hallaba presente en los trabajos mexicanos, puesto que en el caso de Buenos Aires "hay una significativa porción de población que, si bien no reside en urbanizaciones informales o en conjuntos habitacionales, en términos socioeconómicos se ubica en un nivel bajo de la escala social" (Marcos, Mera y Di Virgilio, 2015: 176). 
Figura 4: Urbanizaciones populares de origen informal, barrios cerrados y conjuntos habitacionales de vivienda social. Aglomeración Gran Buenos Aires, 2010

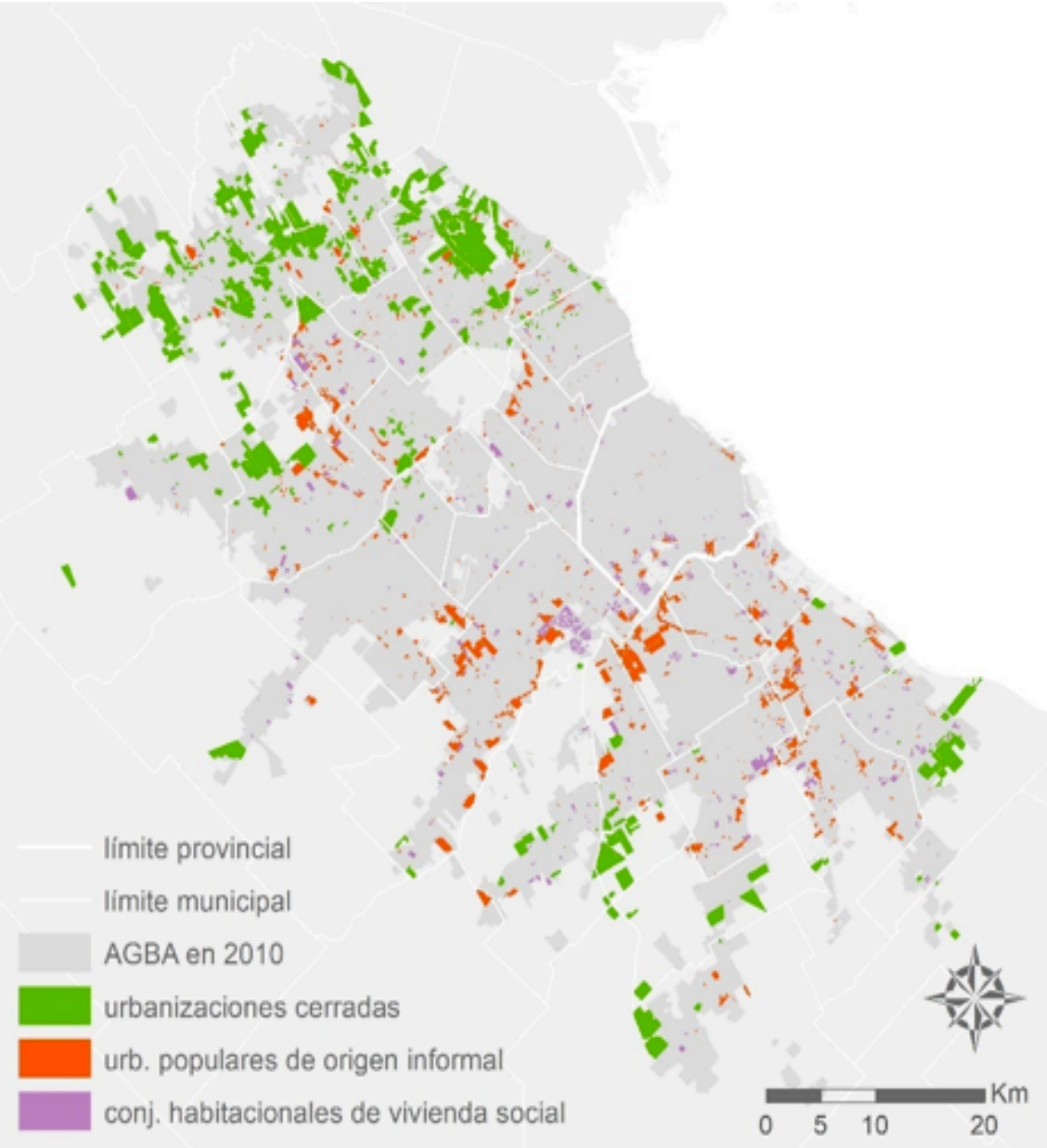

Fuente: elaboración con base en DGEYC, s/f; RPPVA, 2015; urBAsig, s/f; IVBA, 2011; DPOUyT, 2007; Bozzano, 2003; e imágenes satelitales de Google Earth del año 2010.

Sin embargo, el trabajo de la CABA clasificó exclusivamente a las unidades geoestadísticas correspondientes a los fraccionamientos por loteo según su nivel socioeconómico, mientras que aquí se definió como universo la totalidad de las unidades geoestadísticas que componen la aglomeración (al igual que en los trabajos mexicanos), poniendo a los fraccionamientos por loteo formal en el contexto general de la estructura socio-espacial de la ciudad. 
Las técnicas utilizadas para ello fueron el Análisis Factorial de Componentes principales, con la que se resumió los cuatro indicadores originales en uno único con valor propio mayor a 1; y el Análisis de Conglomerados Jerárquico, con la que se clasificaron las unidades espaciales en tres grupos según la distancia euclidiana entre sus puntuaciones factoriales (puntajes $z$ ).

El estudio posterior de los tipos de hábitat bonaerenses no estuvo exento de las limitaciones derivadas del uso de datos censales. Para disponer de la cartografía base de la AGBA a nivel de unidades geoestadísticas pequeñas del último censo de 2010 - que en Argentina reciben el nombre de "radios"-, éstas debieron ajustarse a la superficie de la aglomeración. Así se logró resolver el efecto del PUEM en la delimitación del universo de análisis.

La heterogeneidad en superficie y forma de las unidades geoestadísticas también complejizó la identificación de los tipos de hábitat en la cartografía censal. Para la clasificación de los radios censales mixtos se utilizó la metodología ya empleada en la CABA de explorar de forma complementaria datos de superficie y densidad de cada tipo de hábitat, distribución de las viviendas por tipo y condición de ocupación, y fotointerpretación de imágenes satelitales próximas a la fecha del censo.

Finalmente, las posibilidades de estudiar los atributos de los tipos de hábitat con base en datos censales estuvieron condicionadas por los problemas específicos del censo 2010. A los efectos de simplificar el operativo, abaratar costos y acelerar la obtención de resultados, la metodología del censo 2010 dispuso que en las ciudades de 50 mil habitantes o más se aplicara un cuestionario básico a la totalidad de la población y un cuestionario ampliado más extenso ${ }^{2}$ a una muestra de ella, probabilística a nivel de provincias y departamentos $-\mathrm{y}$ no de unidades geoestadísticas de menor tamaño como los radios-. Es decir que, una vez identificados los tipos de hábitat en la cartografía censal, se dispuso de una cantidad acotada de variables para estudiarlos. Además, se trata de un censo que ha sido objeto de duras críticas en general, por parte de diversos especialistas e instituciones (inclusive del propio INDEC). ${ }^{3}$

La Tabla 1 sintetiza las definiciones de los tipos de hábitat y la metodología empleada en cada caso.

2 El cuestionario ampliado incluye las preguntas del básico y otras sobre la condición migratoria y la situación ocupacional de las personas, fecundidad y seguridad social, entre otras dimensiones y variables.

3 Véanse, por ejemplo, los informes "El futuro Censo Nacional de Población, Hogares y Viviendas" y "Advertencia sobre el uso de series estadísticas" elaborados por la Asociación de Estadios de Población de la Argentina (https://www.redaepa.org.ar) y el INDEC (https://www.indec.gob. ar/), respectivamente. 
Tipos de hábitat: definiciones y desafios para su medición a partir del caso de la aglomeración Gran Buenos Aires / M. MARCOS

Tabla 1: Tipos de hábitat: definiciones y metodología utilizada en la clasificación de las unidades geoestadísticas censales. Aglomeración Gran Buenos Aires, 2010

\begin{tabular}{|c|c|c|}
\hline Definición conceptual & Definición operacional y fuente & Metodología \\
\hline \multicolumn{3}{|l|}{ Ciudad Colonial } \\
\hline $\begin{array}{l}\text { Corresponde a la ciudad de } \\
\text { Buenos Aires a finales de } \\
\text { la Colonia. A lo largo de su } \\
\text { desarrollo el área fue con- } \\
\text { centrando diversos usos del } \\
\text { suelo (residencial, comercial, } \\
\text { administrativo, turístico, de } \\
\text { servicios) y perfiles socioe- } \\
\text { conómicos heterogéneos, y } \\
\text { en la actualidad parte de su } \\
\text { superficie conforma el Área de } \\
\text { Protección Histórica. }\end{array}$ & $\begin{array}{l}\text { Superficie de la AGBA (ciudad } \\
\text { física) en el año1800. } \\
\text { Fuente: cartografía histórica de } \\
\text { Vapñarsky (2000) digitalizada por } \\
\text { Rodríguez y Kosak (2014). }\end{array}$ & $\begin{array}{l}\text { Se superpuso la cartografía } \\
\text { censal (polígonos de radio) } \\
\text { con el polígono de la AGBA } \\
\text { en el año1800, y se clasifica- } \\
\text { ron los radios que contienen la } \\
\text { totalidad o parte de su superfi- } \\
\text { cie dentro de esta área. }\end{array}$ \\
\hline \multicolumn{3}{|l|}{ Expansón de la Ciudad Colonial } \\
\hline $\begin{array}{l}\text { Expansión de la Ciudad } \\
\text { Colonial hacia finales del siglo } \\
\text { XIX. Abarca la totalidad del } \\
\text { litoral de la CABA y el eje de } \\
\text { expansión oeste que aún no } \\
\text { llegaba a los límites actuales } \\
\text { de la CABA. En su conjunto } \\
\text { esta superficie tiene un tejido } \\
\text { urbano heterogéneo en cuanto } \\
\text { a tipo de edificaciones, usos del } \\
\text { suelo y perfil socioeconómico } \\
\text { de sus ocupantes. }\end{array}$ & $\begin{array}{l}\text { Superficie de la AGBA en } \\
\text { 1895, excluyendo a la Ciudad } \\
\text { Colonial. } \\
\text { Fuente: cartografía histórica de } \\
\text { Vapñarsky (2000) digitalizada por } \\
\text { Rodríguez y Kosak (2014). }\end{array}$ & $\begin{array}{l}\text { Se elaboró una envolvente de } \\
\text { población en base al polígono } \\
\text { de la AGBA de } 1895 \text {, que a } \\
\text { su vez se superpuso con la } \\
\text { cartografía censal para clasifi- } \\
\text { car a los radios que contienen } \\
\text { más del } 50 \text { por ciento de su } \\
\text { superficie dentro de esta área } \\
\text { y no pertenecen a la Ciudad } \\
\text { Colonial. }\end{array}$ \\
\hline \multicolumn{3}{|l|}{ Cascos urbanos } \\
\hline $\begin{array}{l}\text { Asentamientos urbanos o } \\
\text { pueblos que se encontraban } \\
\text { separados del área urbanizada } \\
\text { continua de la AGBA en el } \\
\text { pasado y que posteriormente } \\
\text { coalescieron con ella. En la ac- } \\
\text { tualidad se caracterizan por sus } \\
\text { elevados niveles de consolida- } \\
\text { ción urbana y pueden constituir } \\
\text { subcentralidades o cabeceras } \\
\text { municipales. }\end{array}$ & $\begin{array}{l}\text { Asentamientos urbanos o } \\
\text { pueblos que se incorporaron a } \\
\text { la AGBA entre } 1895 \text { y } 1948, \text { y } \\
\text { que en la actualidad se caracte- } \\
\text { rizan por sus elevados niveles } \\
\text { de consolidación urbana y } \\
\text { pueden constituir subcentrali- } \\
\text { dades o cabeceras municipales. } \\
\text { Se incluyen tres cohortes de } \\
\text { cascos urbanos, definidas como } \\
\text { tales por el periodo en que } \\
\text { se conurbaron con la AGBA: } \\
\text { entre } 1895 \text { y } 1910 \text {, entre } 1910 \\
\text { y } 1948, \text { y después de } 1948 . \\
\text { Fuente: cartografía de los años } \\
\text { 1895, 1910 y } 1948 \text { de Vapñarsky } \\
\text { (2000) parcialmente digitalizada } \\
\text { por Rodríguez y Kosak (2014) y } \\
\text { completada en el marco de este } \\
\text { estudio. }\end{array}$ & $\begin{array}{l}\text { Se superpuso la cartografía } \\
\text { censal con la cartografía } \\
\text { histórica y se clasificaron los } \\
\text { radios que contienen más del } \\
50 \text { por ciento de su super- } \\
\text { ficie abarcada por antiguos } \\
\text { asentamientos urbanos o } \\
\text { pueblos que en la actualidad } \\
\text { se encuentran dentro de los } \\
\text { límites de la AGBA. }\end{array}$ \\
\hline
\end{tabular}


Tabla 1: Continuación

\begin{tabular}{|c|c|c|}
\hline Definición conceptual & Definición operacional y fuente & Metodología \\
\hline \multicolumn{3}{|c|}{ Urbanizaciones populares de origen informal } \\
\hline $\begin{array}{l}\text { Urbanizaciones producidas por } \\
\text { modalidades de poblamiento } \\
\text { popular que se caracterizan } \\
\text { por su localización en tierras } \\
\text { degradadas, la irregularidad } \\
\text { inicial en la ocupación del } \\
\text { suelo, la escasa o nula infraes- } \\
\text { tructura urbana y de servicios, } \\
\text { y el predominio de viviendas } \\
\text { de autoconstrucción. Pueden } \\
\text { ser heterogéneos en cuanto } \\
\text { a la regularidad de su trama, } \\
\text { su densidad poblacional y el } \\
\text { nivel de consolidación de las } \\
\text { viviendas y de provisión de in- } \\
\text { fraestructura y servicios, dando } \\
\text { lugar a subtipos. }\end{array}$ & $\begin{array}{l}\text { Se incluyen dos tipos de urba- } \\
\text { nizaciones populares de origen } \\
\text { informal existentes en Buenos } \\
\text { Aires: } \\
\text { 1. Villas: a) producto de la ocu- } \\
\text { pación informal de tierra urba- } \\
\text { na vacante o tierras fiscales; b) } \\
\text { trama irregular no amanzanada } \\
\text { organizada en intrincados pasi- } \\
\text { llos; c) viviendas de materiales } \\
\text { precarios o de desecho; d) } \\
\text { alta densidad poblacional; e) } \\
\text { escaso o nulo espacio verde; f) } \\
\text { infraestructura autoprovista. } \\
\text { 2. Asentamientos: a) produc- } \\
\text { to de la ocupación informal } \\
\text { decidida y organizada de tierra } \\
\text { estatal o privada; b) trama con } \\
\text { tendencia a ser regular y pla- } \\
\text { nificada; c) ocupantes buscan } \\
\text { legitimarse como propietarios; } \\
\text { d) viviendas con algún nivel de } \\
\text { firmeza. } \\
\text { Fuente: cartografia de villas y asen- } \\
\text { tamientos de la CABA (DGEyC, } \\
\text { s/f) y de la Provincia de Buenos } \\
\text { Aires (RPPVA, 2015).* }\end{array}$ & $\begin{array}{l}\text { Se superpuso la cartografía } \\
\text { censal con la de villas y asen- } \\
\text { tamientos, y se clasificaron } \\
\text { las unidades geoestadísticas } \\
\text { en las que prepondera (por } \\
\text { superficie o densidad) el tipo } \\
\text { de hábitat en cuestión. En el } \\
\text { caso de radios mixtos, se con- } \\
\text { sultaron datos de superficie } \\
\text { abarcada por cada tipología } \\
\text { y se verificaron densidades } \\
\text { relativas a través de imágenes } \\
\text { satelitales de } 2010 \text {. }\end{array}$ \\
\hline
\end{tabular}

* En el caso de la CABA, se consideraron urbanizaciones populares de origen informal a las villas, asentamientos y núcleos habitacionales transitorios. En tanto que, en la Provincia de Buenos Aires, se consideró lo que en la fuente aparece como villas, villas consolidadas y otros tipos de villas (conjuntos habitacionales tugurizados, fábricas tomadas, etc.) y como asentamientos, loteos clandestinos y asentamientos históricos consolidados; se excluyeron las situaciones de informalidad dispersa, los conjuntos habitacionales "tomados", las villas y asentamientos regularizados, otras ocupaciones no identificadas (ocupaciones en camino de sirga, etcétera) y otras situaciones de precariedad (fábricas tomadas, etcétera). 
Tipos de hábitat: definiciones y desafios para su medición a partir del caso de la aglomeración Gran Buenos Aires / M. MARCOS

Tabla 1: Continuación

\begin{tabular}{|c|c|c|}
\hline Definición conceptual & Definición operacional y fuente & Metodología \\
\hline \multicolumn{3}{|l|}{ Urbanizaciones cerradas } \\
\hline $\begin{array}{l}\text { Emprendimientos } \\
\text { urbanísticos de acceso } \\
\text { restringido por muros } \\
\text { y barreras vigiladas } \\
\text { destinados a residencia } \\
\text { principal o secundaria } \\
\text { de hogares de ingresos } \\
\text { medio-altos y altos. En } \\
\text { general son promovidos } \\
\text { por grandes desarro- } \\
\text { lladores urbanos y se } \\
\text { ubican en áreas subur- } \\
\text { banas próximas a vías } \\
\text { rápidas de circulación. } \\
\text { El tamaño de los lotes y } \\
\text { la infraestructura de uso } \\
\text { común de los residentes } \\
\text { pueden diferir en gran } \\
\text { medida de acuerdo al } \\
\text { subtipo de urbanización } \\
\text { cerrada y al sector social } \\
\text { al que estén destinadas. } \\
\text { En todos los casos el es- } \\
\text { pacio público se encuen- } \\
\text { tra privatizado, puesto } \\
\text { que se impide que las } \\
\text { calles y lugares de } \\
\text { recreación sean usados } \\
\text { libremente por personas } \\
\text { ajenas al barrio. }\end{array}$ & $\begin{array}{l}\text { Se incluyen tres tipos de urbani- } \\
\text { zaciones cerradas existentes en } \\
\text { Buenos Aires (Roitman, 2003): } \\
\text { 1. Countries: urbanizaciones } \\
\text { cerradas de tamaño variable con } \\
\text { vigilancia y seguridad permanentes. } \\
\text { Pueden existir (o no) dependen- } \\
\text { cias de uso colectivo, tales como } \\
\text { club-house o instalaciones depor- } \\
\text { tivas. } \\
\text { 2. Clubes de campo: las instalacio- } \\
\text { nes deportivas y las actividades que } \\
\text { se realizan en ellas (principalmente } \\
\text { polo y golf) son un eje esencial de } \\
\text { la vida del barrio y su característica } \\
\text { distintiva. El ingreso y la residencia } \\
\text { en el barrio requieren de membresía } \\
\text { y aceptación de los demás socios, y } \\
\text { supone costos financieros en con- } \\
\text { cepto de expensas y cuotas sociales } \\
\text { más elevados que otros tipos de } \\
\text { barrios. } \\
\text { 3. Chacras: modalidad relacio- } \\
\text { nada con un estilo de vida menos } \\
\text { urbano y con mayor contacto con } \\
\text { la naturaleza. Los terrenos son lo } \\
\text { suficientemente amplios como para } \\
\text { poder realizar pequeños cultivos en } \\
\text { su interior. } \\
\text { Fuentes: cartografia de urbanizaciones } \\
\text { cerradas (urBAsig, s/f), que incluye aquellas } \\
\text { aprobadas por la Dirección Provincial de Or- } \\
\text { denamiento Urbano y Territorial y la Dirección } \\
\text { de Asuntos Municipales, como urbanizacio- } \\
\text { nes no aprobadas pero identificadas a fines } \\
\text { impositivos por la Agencia de Recaudación } \\
\text { de la Provincia de Buenos Aires; imágenes } \\
\text { satelitales de Google Earth del año } 2010 .\end{array}$ & $\begin{array}{l}\text { Se superpuso la carto- } \\
\text { grafía censal con la } \\
\text { cartografía de urbani- } \\
\text { zaciones cerradas y se } \\
\text { clasificaron las uni- } \\
\text { dades geoestadísticas } \\
\text { en las que prepondera } \\
\text { (por superficie o } \\
\text { densidad) el tipo de } \\
\text { hábitat en cuestión. } \\
\text { Además, se identifi- } \\
\text { caron y registraron } \\
\text { barrios adicionales no } \\
\text { incluidos en la fuente, } \\
\text { mediante fotointer- } \\
\text { pretación de Google } \\
\text { Earth (2010). }\end{array}$ \\
\hline
\end{tabular}


Tabla 1: Continuación

\begin{tabular}{|c|c|c|}
\hline Definición conceptual & Definición operacional y fuente & Metodología \\
\hline \multicolumn{3}{|c|}{ Conjuntos habitacionales de vivienda social } \\
\hline $\begin{array}{l}\text { Conjuntos de viviendas } \\
\text { multifamiliares o unifa- } \\
\text { miliares construidas en } \\
\text { serie y financiadas total } \\
\text { o parcialmente por el } \\
\text { sector público. Los espa- } \\
\text { cios resultantes pueden } \\
\text { ser de distinta densidad } \\
\text { y en general se caracte- } \\
\text { rizan por su homogenei- } \\
\text { dad interna. }\end{array}$ & $\begin{array}{l}\text { Conjuntos de viviendas multifami- } \\
\text { liares o unifamiliares construidas en } \\
\text { serie y financiadas de forma total o } \\
\text { parcial con recursos públicos, con } \\
\text { el objetivo de brindar una solución } \\
\text { habitacional definitiva a los hogares } \\
\text { adjudicatarios. Se incluyen tres } \\
\text { modalidades: } \\
\text { 1) financiamiento y construcción } \\
\text { pública directa } \\
\text { 2) financiamiento público y } \\
\text { construcción vía organizaciones } \\
\text { intermedias } \\
\text { 3) financiamiento público de desa- } \\
\text { rrollos promovidos por instituciones } \\
\text { hipotecarias. } \\
\text { Fuentes: cartografía de conjuntos habitaciona- } \\
\text { les de la DGEyC (s/f) de la CABA; registros } \\
\text { de conjuntos habitacionales del IVBA (2011) y } \\
\text { la DPOUyT (2007) de la Provincia de Buenos } \\
\text { Aires; Atlas Metropolitano de Buenos Aires } \\
\text { (Bozzano, 2003); imágenes satelitales de } \\
\text { Google Earth del año 2010. }\end{array}$ & $\begin{array}{l}\text { Se superpuso la } \\
\text { cartografía censal } \\
\text { con la cartografía de } \\
\text { conjuntos habitacio- } \\
\text { nales y se clasifi- } \\
\text { caron las unidades } \\
\text { geoestadísticas en las } \\
\text { que prepondera (por } \\
\text { superficie o densidad) } \\
\text { el tipo de hábitat en } \\
\text { cuestión. Además, se } \\
\text { identificaron y regis- } \\
\text { traron barrios adicio- } \\
\text { nales no incluidos en } \\
\text { la fuente, mediante } \\
\text { fotointerpretación de } \\
\text { Google Earth (2010). }\end{array}$ \\
\hline
\end{tabular}

\section{Análisis de Resultados}

A primera vista, la AGBA se presenta como un espacio residencial urbano atravesado por profundas desigualdades que aquí han quedado plasmadas en su estratificación socio-espacial (Figura 5). Esta representación da cuenta de las diferencias que imprimen en el territorio quienes se asientan en él, pero de ningún modo es la división social del espacio residencial, en el sentido de que el mapa no es el territorio, sino una elaboración en la que se han puesto en juego cuestiones determinantes de los resultados (Harley, 2005): el recorte del universo, la utilización de unidades espaciales de análisis con atributos de forma, tamaño y delimitación particulares, la definición conceptual y operacional del nivel socioeconómico de la población y las técnicas estadísticas. 
Tipos de hábitat: definiciones y desafíos para su medición a partir del caso de la aglomeración Gran Buenos Aires / M. MARCOS

Tabla 1: Continuación

\begin{tabular}{|c|c|c|}
\hline Definición conceptual & Definición operacional y fuente & Metodología \\
\hline \multicolumn{3}{|c|}{ Fraccionamientos por loteo formal de nivel socioeconómico alto, medio y bajo } \\
\hline $\begin{array}{l}\text { Zonas residenciales que } \\
\text { se originaron a partir de la } \\
\text { suburbanización de la ciudad } \\
\text { en base a la subdivisión y } \\
\text { venta de lotes o parcelas } \\
\text { para uso habitacional en } \\
\text { apego a la normativa (que } \\
\text { no siempre exigió infraes- } \\
\text { tructura urbana completa } \\
\text { previa). La vivienda es } \\
\text { unifamiliar (de construcción } \\
\text { autogestionada e inclusive } \\
\text { de autoconstrucción) o en } \\
\text { propiedad horizontal (cons- } \\
\text { truida por desarrolladores } \\
\text { privados), y fue construida } \\
\text { antes de ser ocupada. Se } \\
\text { pueden distinguir áreas rela- } \\
\text { tivamente homogéneas en su } \\
\text { interior y heterogéneas entre } \\
\text { sí según el nivel socioeconó- } \\
\text { mico de los residentes, que } \\
\text { suele estar correlacionado } \\
\text { con el nivel de provisión de } \\
\text { servicios e infraestructuras } \\
\text { urbanas. }\end{array}$ & $\begin{array}{l}\text { Zonas residenciales que se } \\
\text { originaron a partir la subdivi- } \\
\text { sión y venta autorizada de lotes } \\
\text { o parcelas para uso habitacional } \\
\text { en apego a la normativa, y que } \\
\text { no se corresponden con los tipos } \\
\text { de hábitat anteriores, pero se } \\
\text { diferencian internamente por el } \\
\text { nivel socioeconómico, definido } \\
\text { a partir de: la disponibilidad de } \\
\text { agua de red pública dentro de } \\
\text { las viviendas; la utilización de } \\
\text { gas de red, gas a granel o gas en } \\
\text { tubo; la posesión de computado- } \\
\text { ra en la vivienda; y el porcen- } \\
\text { taje de población con estudios } \\
\text { universitarios. } \\
\text { Fuente: INDEC, 2010, Censo } \\
\text { Nacional de Población, Hogares y } \\
\text { Viviendas. }\end{array}$ & $\begin{array}{l}\text { Se clasificó en } \\
\text { esta categoría a las } \\
\text { unidades geoes- } \\
\text { tadísticas que no } \\
\text { quedaron incluidas } \\
\text { en las anteriores y se } \\
\text { distinguieron en su } \\
\text { interior tres nieles } \\
\text { socioeconómicos con } \\
\text { base en los atributos } \\
\text { de los hogares y las } \\
\text { personas según el } \\
\text { Censo 2010. }\end{array}$ \\
\hline
\end{tabular}

De las 13 ' 588,171 personas con que contaba la ciudad en 2010,15 por ciento (algo más de dos millones, según la Tabla 2) pertenecen al estrato socio-residencial alto conformado por el centro y norte de la CABA, el litoral de los municipios costeros del norte (Vicente López y San Isidro) y algunos ejes más delgados a lo largo de las vías de comunicación ferroviarias. Desde este núcleo, el nivel socioeconómico se degrada progresivamente hacia la periferia, y las áreas de nivel socioeconómico medio alto y medio, que reúnen unos cuatro millones 600 mil habitantes, son la antesala de las áreas exteriores e intersticiales más degradadas, en las que se asientan casi siete millones de personas (la mitad de la población de la metrópoli). 
Figura 5: Estratificación socio-espacial. Aglomeración Gran Buenos Aires, 2010

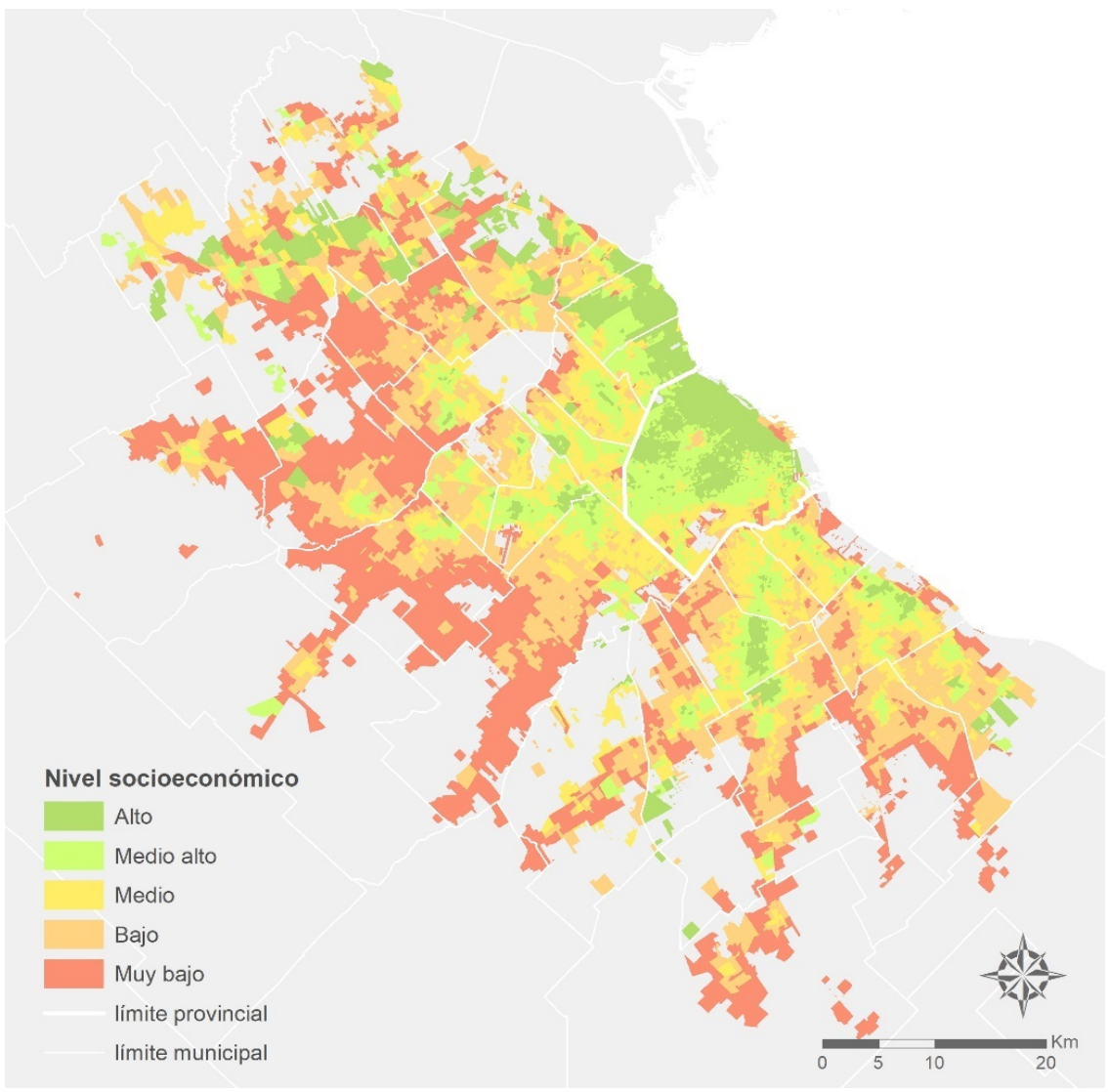

Fuente: elaboración con base en INDEC, Censo Nacional de Población, Hogares y Viviendas 2010.

Esta estructura socio-espacial preponderante se ve interrumpida por bolsones de pobreza próximos a las áreas centrales de nivel socioeconómico alto (en especial, en el sur de la CABA) y por bolsones de riqueza localizados en la periferia de la ciudad (en particular, en el norte), que fragmentan áreas residenciales que hasta hace unas pocas décadas se encontraban reservadas para los sectores populares.

La estructura socio-espacial obtenida en la Figura 5 es una representación estática de la división social del espacio residencial, resultante de la compleja dinámica de las relaciones socio-espaciales de producción (Duhau y Giglia, 2008; Lefebvre, 1972). En términos de Giddens (1984), el 
espacio social metropolitano así estratificado es un agenciamiento humano - y a la vez parte del medio estructural en el que la agencia tiene lugarcuya producción está signada por el devenir inconcluso de luchas, conflictos y contradicciones que subyacen a la Figura 5, pero que ella por sí sola no permite más que intuir.

Tabla 2: Tipos de hábitat: superficie, población y densidad. Aglomeración Gran Buenos Aires*, año 2010

\begin{tabular}{|c|c|c|c|}
\hline Tipo de hábitat & $\begin{array}{r}\text { Superficie } \\
\left(\mathrm{km}^{2}\right)\end{array}$ & $\begin{array}{r}\text { Población } \\
\text { (miles) }\end{array}$ & Densidad \\
\hline Total & $2,445.1$ & $13,588.2$ & $5,557.3$ \\
\hline Ciudad colonial (1800) & 10.6 & 203.2 & $19,141.4$ \\
\hline $\begin{array}{l}\text { Expansión de la ciudad colonial } \\
\text { (1895) }\end{array}$ & 78.0 & $1,556.4$ & $19,966.2$ \\
\hline Casco urbano conurbado & 70.4 & 425.2 & $6,036.3$ \\
\hline $\begin{array}{l}\text { Urbanización popular de origen } \\
\text { informal }\end{array}$ & 116.4 & 906.9 & $7,789.4$ \\
\hline Urbanización cerrada & 224.2 & 146.7 & 654.2 \\
\hline $\begin{array}{l}\text { Conjunto habitacional de vivienda } \\
\text { social }\end{array}$ & 63.3 & 565.9 & $8,941.4$ \\
\hline \multirow{3}{*}{$\begin{array}{l}\text { Fraccionamiento por } \\
\text { loteo formal de nivel } \\
\text { socioeconómico }\end{array}$} & 90.5 & 674.1 & $7,449.9$ \\
\hline & 517.2 & $3,371.7$ & $6,519.1$ \\
\hline & $1,274.4$ & $5,738.1$ & $4,502.4$ \\
\hline
\end{tabular}

* Excluye cuatro unidades geoestadísticas sin población.

Fuente: elaboración con base en fuentes especificadas en la Tabla 1.

El concepto de "tipo de hábitat" viene precisamente a oficiar de eslabón intermedio entre el espacio producto y los procesos que lo estructuraron como tal. Introduce en el análisis categorías vinculadas con el progresivo poblamiento del territorio y con la forma en que diferentes actores contribuyeron a la producción de la ciudad, según su capacidad para acceder al suelo y construir viviendas en el marco de las regulaciones del mercado inmobiliario y las políticas públicas específicas e indirectas.

El núcleo inicialmente poblado de la ciudad, o "ciudad colonial" es un espacio compacto de aproximadamente diez kilómetros cuadrados y más de 200 mil habitantes, constituido por un mosaico de unidades geoestadísticas censales de nivel socioeconómico medio o superior (Tabla 2 y Figura 6) sumamente denso (19 mil habitantes por kilómetro cuadrado). 
Figura 6: Estratificación socio-espacial de la ciudad colonial y su expansión hacia 1895. Buenos Aires, 2010

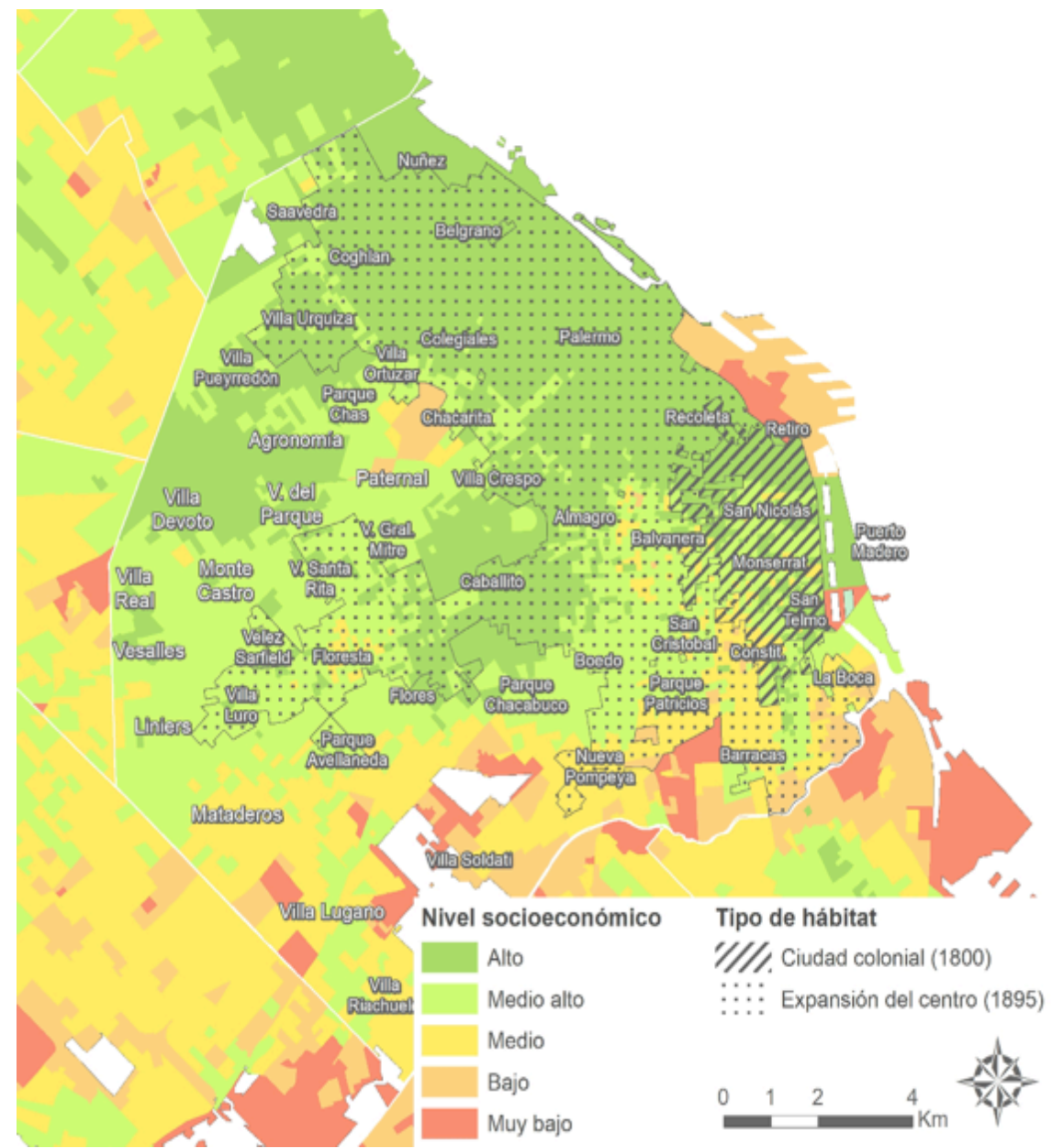

Fuente: elaboración con base en Vapñarsky, 2000 (digitalizado por Rodríguez y Kosak, 2014) e INDEC, Censo Nacional de Población, Hogares y Viviendas 2010.

Se pudo identificar en la cartografía censal con relativa exactitud a pesar del PUEM, quedando incluidos 1.6 kilómetros cuadrados no pertenecientes a la AGBA en 1800). Sin embargo, el tamaño de las unidades geoestadísticas sí constituyó un impedimento para captar la heterogeneidad de la condición socioeconómica de este entorno complejo, que incluye el uso residencial, pero también tiene atractivo turístico y es sede de las principales instituciones de la administración pública y del poder 
económico. Usos y funciones diversos con sus respectivos equipamientos y actividades aparecen yuxtapuestos. Ello configuró un espacio que ha atravesado procesos de densificación, verticalización y modernización de los sectores avocados a la administración y los negocios (Ciccolella y Vecslir, 2012); y de renovación y revalorización parcial de los sectores patrimoniales protegidos (abandonados por las clases altas hacia finales del siglo XIX, ocupados luego por población inmigrante y de bajos recursos (Orueta et al, 2003) y sujetos a lógicas gentrificadoras en los años previos a la pandemia de Covid-19 (Pérez y Fernández, 2014)). En la actualidad, tras el vaciamiento de las oficinas y los comercios durante la emergencia sanitaria, su futuro es incierto (Quiroga y Casali, 2021). Los problemas de precariedad habitacional no resuelta incluyen situaciones de hacinamiento, falta de ventilación y escases de servicios y deterioro edilicio en viviendas unifamiliares, inquilinatos, hoteles pensión y casas tomadas (Mazzeo, Lago y Wainer, 2008). Su distribución espacial relativamente dispersa hace que pasen desapercibidas en los agregados residenciales que determinan las unidades geoestadísticas censales, pero no así en un indicador clásico de necesidades básicas insatisfechas, que revela tener una incidencia de 11 por ciento en este tipo de hábitat (Tabla 3).

La primera expansión de la ciudad colonial dio lugar hacia el año 1895 a una Buenos Aires que apenas rebasaba los actuales límites de la CABA hacia el sur (Figura 6) y hoy es el espacio residencial pericentral (Goicoechea y Abba, 2020) de más de un millón y medio de personas. Para la última década del siglo XIX la ciudad había crecido anexando un anillo compacto de tierras en torno al casco colonial original, a partir del que se desplegaban dos ejes bien definidos: el más compacto y desarrollado de ellos sobre la ribera norte y el segundo hacia el oeste. Los sectores centro-oeste y norte de esta primera expansión del casco colonial se consolidaron progresivamente y en la actualidad se destacan por su verticalización, su dotación de infraestructura y servicios urbanos, su conectividad y la homogeneidad de su composición social de nivel medio alto y alto. Hacia el sur, en cambio, el panorama está marcado por la heterogeneidad. En un extremo, el eje revalorizado - y geográficamente acotado- del barrio de Barracas fue dinamizado por el sector privado a través de la promoción de su buena conectividad, los desarrollos habitacionales nuevos y el reciclaje de galpones y depósitos. 


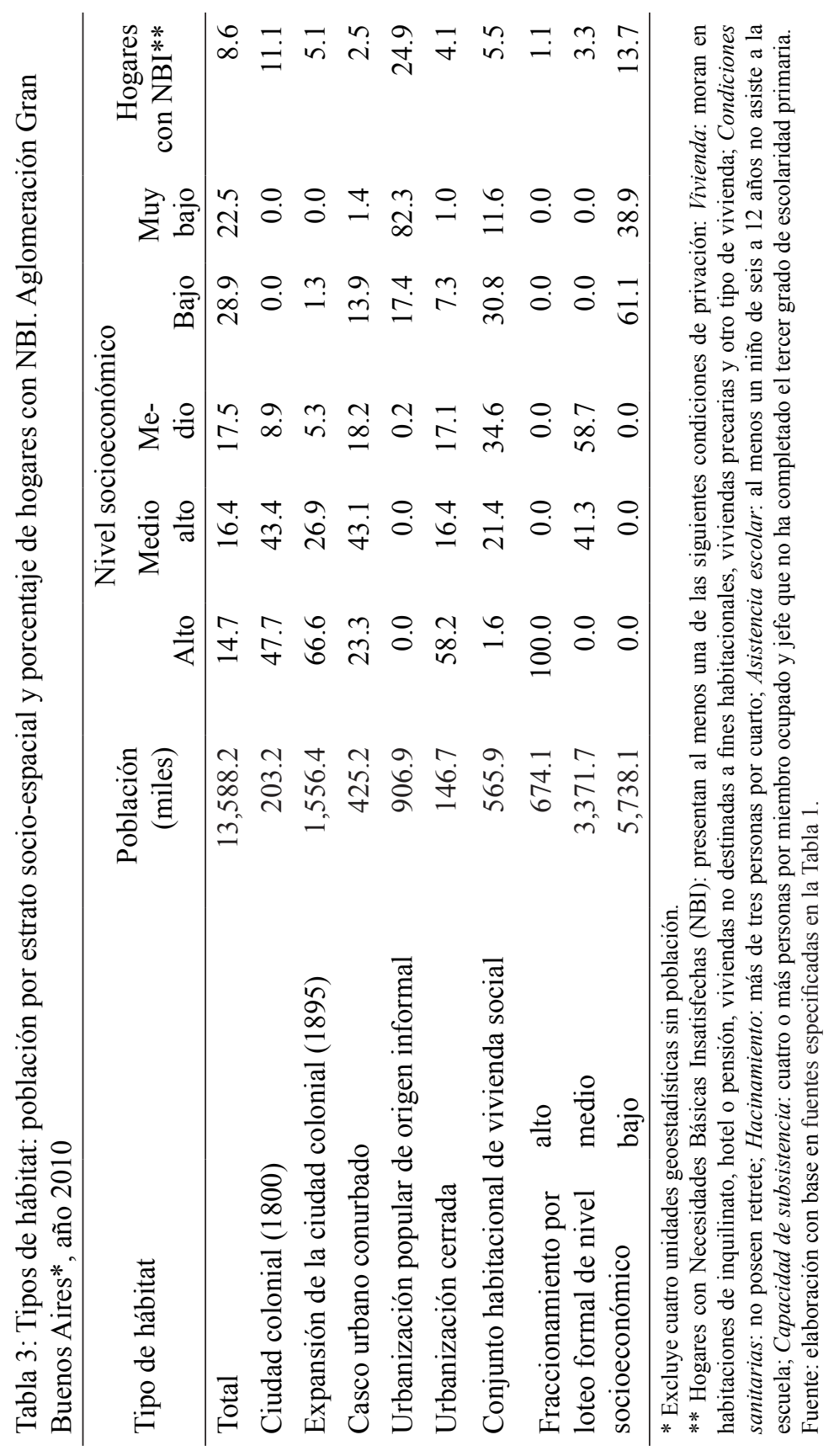


Y, en el extremo opuesto, los espacios siempre deprimidos del barrio de La Boca recibieron inversión pública para solucionar problemas estructurales como las inundaciones, pero muchas viviendas continúan en situación de deterioro y ocupadas por los estratos sociales más bajos de la población, y se entremezclan con industrias, depósitos y el puerto actualmente en desuso y situación de abandono (Orueta et al, 2003; Ostuni, et al, 2008).

A diferencia de lo que ocurría con la Ciudad Colonial, la escala barrial en la que se presentan estos fenómenos de degradación permite que los datos censales agregados en radios puedan reflejan la heterogeneidad socio-residencial de la expansión de la ciudad colonial.

Los cascos urbanos conurbados con la AGBA a lo largo del siglo XX conservan la identidad que les confirió su pasado de pueblos independientes, localizados a lo largo de los caminos reales y trazados ferroviarios que convergían en el centro de la metrópoli. En torno a muchos de ellos se han organizado municipios de los cuales son cabecera administrativa y centro. A nivel metropolitano, cumplen la función de subcentralidades tradicionales que alojan sedes de administraciones locales y están dotadas de centros comerciales a cielo abierto (diferenciadas de las centralidades de nuevo tipo que han emergido con posterioridad) (Abba, 2008; Ciccolella y Vecslir, 2012). La calidad del espacio público es buena, pero puede variar de un casco a otro según la revitalización y regeneración que hayan promovido las respectivas administraciones locales. Estas características hacen de los cascos conurbados pequeños espacios residenciales de nivel socioeconómico alto y medio alto (con preponderancia de este último) y relativamente verticalizados y densos - aunque sin alcanzar los niveles de la ciudad colonial y su primera expansión-. Sin embargo, por fuera de ellos (en particular en los cascos más exteriores de la metrópolis) la condición socioeconómica del espacio residencial se degrada rápidamente hacia la periferia. Esto último, sumado a que las unidades espaciales censales no se ajustan con exactitud a sus límites exteriores, explica la presencia de población en estratos socio-espaciales bajos o muy bajos (15 por ciento) en los cascos conurbados.

Otros tipos de hábitat, como las urbanizaciones populares de origen informal, las urbanizaciones cerradas y los conjuntos habitacionales de vivienda social, comparten a nivel teórico el hecho de estar definidos por el modo de producción del espacio habitacional; y a nivel metodológico la dificultad de que, en general, asumen la forma de pequeños polígonos dispersos a los que la cartografía censal raramente se ajusta con exactitud. 
Es así que los datos de superficie, población, densidad, condición socioeconómica y necesidades básicas de estos entornos (tablas 2 y 3 ) son más estimativos que en otros casos.

Las urbanizaciones populares de origen informal se encuentran fundamentalmente en el sur de la CABA y en las zonas intersticiales de la primera y la segunda corona de municipios sobre los que se despliega la aglomeración. Las villas hicieron su aparición en la ciudad hacia finales de la década de 1930, como alternativa — supuestamente transitoria - dentro de la trama urbana para acceder al incipiente y promisorio mercado de trabajo industrial que por entonces dinamizaba las migraciones campo-ciudad. Los asentamientos, en cambio, son una tipología de hábitat popular de origen informal más reciente, que comenzó a desarrollarse en la década de 1980 en zonas intersticiales de la primera y — en menor medida — segunda corona de municipios que rodean a la CABA ante el endurecimiento de las condiciones para fraccionar el suelo periférico y poner a la venta los lotes en apego a la normativa vigente (Cravino, 2006, 2009). Es decir que las urbanizaciones populares de origen informal tienen una localización próxima a áreas centrales en términos euclidianos, pero distante en términos de tiempo de viaje y fronteras físicas y simbólicas con respecto al resto de la trama urbana.

Su identificación en la cartografía censal siguiendo los criterios descritos en la metodología permitió obtener datos que tienen, a la vez, la ventaja de remitir a superficies que corresponden en gran medida a este tipo de hábitat y la desventaja de que los niveles de exigencia adoptados supusieron la pérdida de mucha información. La cartografía censal se ajusta en buena medida a las urbanizaciones de origen informal de mayor superficie en respuesta a la necesidad de contar con información sobre ellas $\mathrm{y}$, en el caso particular de las villas, a la necesidad de adaptar el operativo de relevamiento de los datos a una trama urbana intrincada y de difícil acceso (Figura 7). Pero no sucede lo mismo cuando las urbanizaciones se encuentran dispersas y son de pequeño tamaño y más recientes (Figura 7). En este último caso, es común que ocupen una pequeña porción de la superficie de las unidades geoestadísticas y no se puedan estudiar a partir de datos censales.

En consecuencia, la caracterización de este tipo de hábitat que se ha logrado corresponde a sus atributos en términos relativos (bajo el supuesto de que las urbanizaciones informales excluidas son similares a las incluidas), pero los valores absolutos subestiman su magnitud. 
Figura 7: Urbanizaciones populares de origen informal: heterogeneidad de tamaños y contigüidad espacial en zonas de distinto nivel de densidad. Aglomeración Gran Buenos Aires, año 2010

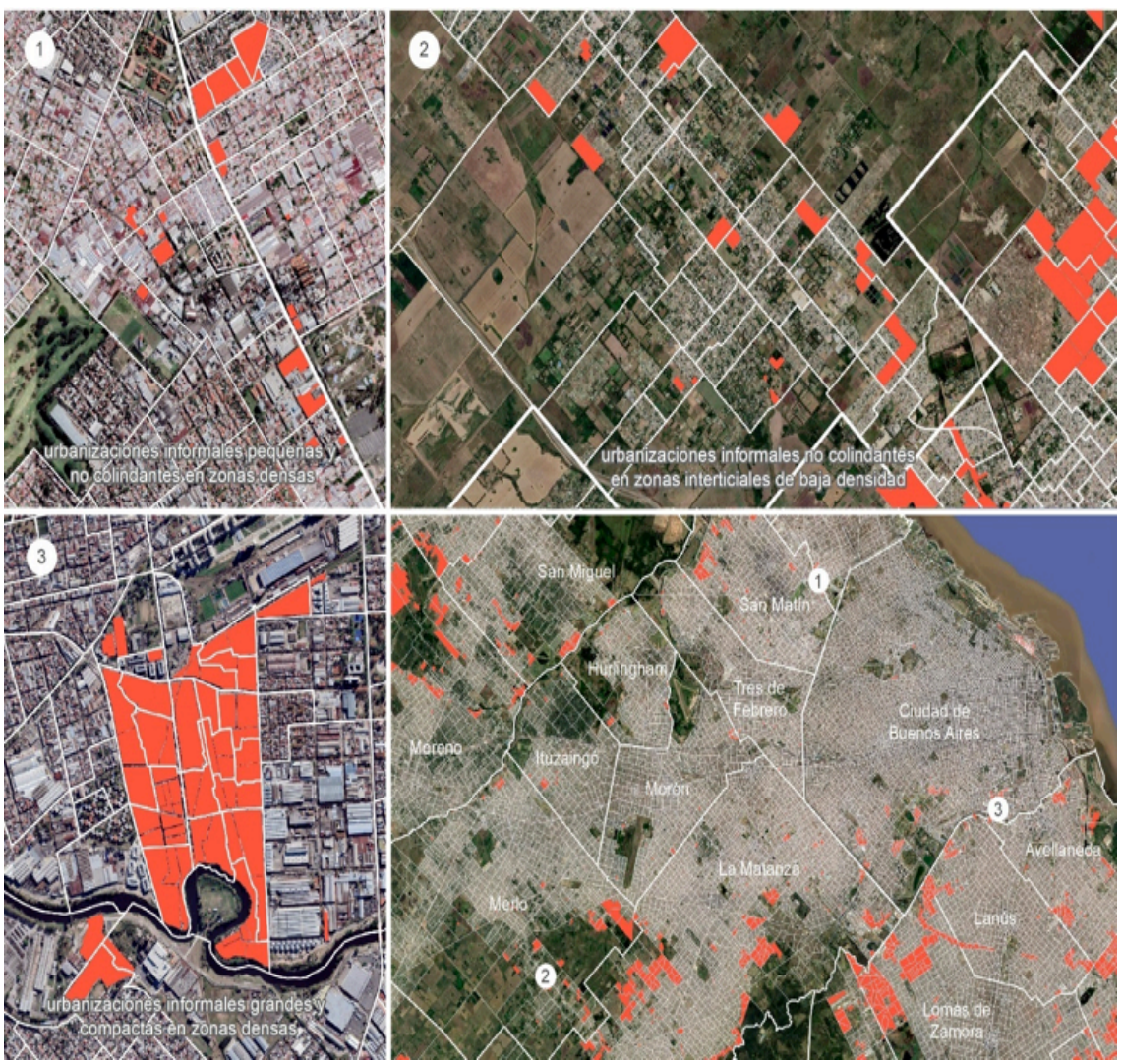

Fuente: elaboración con base en cartografía censal; DGEyC, s/f; RPPVA, 2015; e imágenes satelitales de Google Earth.

Así lo confirma la contrastación de las cifras de la Tabla 2 con las que se pueden rastrear en los antecedentes: según resultados obtenidos aquí, en 2010 las urbanizaciones populares de origen informal tenían unos 900 mil habitantes, valor muy por debajo del cálculo realizado por Cravino, Del Río y Duarte (2010) para el año 2006, cuando ya registraban más de un millón de habitantes en las urbanizaciones informales de la CABA y 24 de los municipios que la rodean, o del valor que se desprende del Relevamiento de Asentamientos Informales realizado por la organización no gubernamental TECHO en el año 2016, que contabilizó 508 mil familias 
en la AGBA (Gabosi, Dattoli y Pérez, 2011) que — según el tamaño medio de los hogares- equivaldrían a 1 millón 900 mil personas.

La densidad de casi 7,800 habitantes por kilómetro cuadrado ubica a este tipo de hábitat por encima de la densidad promedio de la AGBA. A su vez, este valor general oculta la aún más elevada densidad relativa de las villas, dada por su verticalización —más frecuente en la CABA—, la estrechez de las vías de comunicación internas y la casi total ocupación de la superficie de las parcelas.

La preponderancia de estratos socio-espaciales de nivel socioeconómico bajo (17 por ciento) y muy bajo (82 por ciento) en las urbanizaciones de origen informal es consistente con lo esperado y abona la afirmación de que los valores relativos son de gran exactitud. En este tipo de hábitat también se registraron los niveles de necesidades básicas insatisfechas más altos ( 25 por ciento), que dan cuenta de que constituyen importantes bolsones de pobreza estructural.

En el otro extremo de la escala socio-residencia, las urbanizaciones cerradas se encuentran localizadas en la periferia sur y, particularmente, norte de la aglomeración, a la vera de autopistas y otros accesos viales importantes (Figura 8). Aparecen fragmentando los espacios residenciales más degradados de la ciudad y en muchos casos trazan el borde exterior de la metrópoli.

Su identificación en la cartografía censal se vio dificultada por el gran tamaño de las unidades geoestadísticas en el borde exterior de la ciudad, donde, dada la baja densidad poblacional, el INDEC subdividió el territorio provincial en menor medida de cara a la recolección de los datos. La población y la superficie que corresponde a zonas rurales pudo ser eliminada - especificando como universo a la población de la aglomeración al realizar consultas en la base de datos censal, en el primer caso, y mediante el ajuste de la geometría de los radios originales a la envolvente de población de la AGBA en 2010, en el segundo-.

Pero cuando la superficie de las unidades espaciales contiene más de un tipo de hábitat, se debió aplicar los criterios de preponderancia especificados en la metodología.

El hecho de que, a pesar de tratarse por definición de un entorno residencial de nivel socioeconómico alto, la distribución de la población por estrato socio-residencial no lo refleja, se debe también al modo en que se midió la composición social: dos de los cuatro indicadores utilizados remiten a la provisión de servicios que en Buenos Aires se han ido expandiendo desde el centro hacia la periferia, y no alcanzaron a muchos de los municipios exteriores en los que se encuentran las urbanizaciones cerradas. 
Tipos de hábitat: definiciones y desafíos para su medición a partir del caso de la aglomeración Gran Buenos Aires / M. MARCOS

Figura 8: Tipos de hábitat de la Aglomeración Gran Buenos Aires, 2010

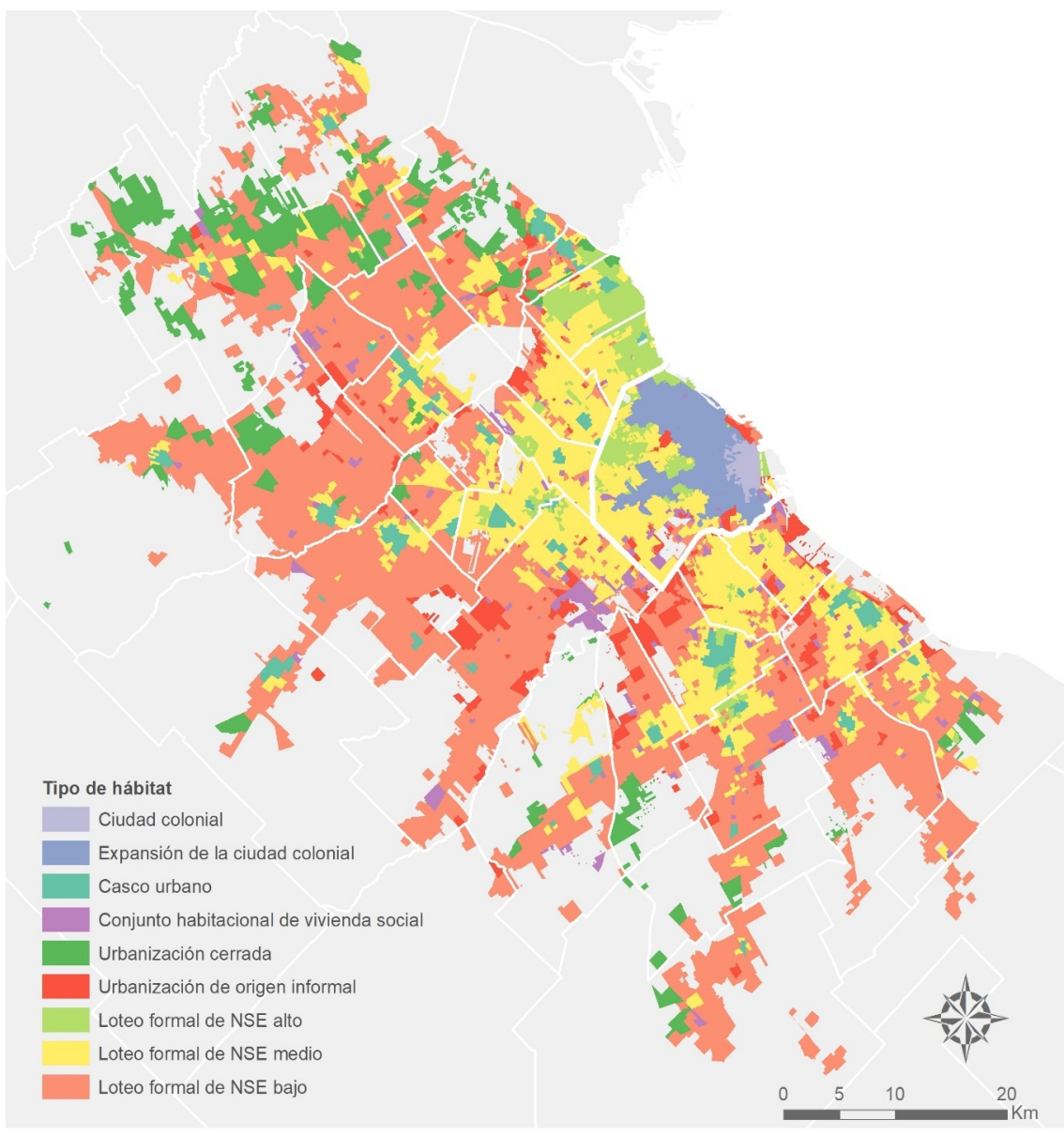

Fuente: elaboración con base en fuentes especificadas en la Tabla 1. 
En síntesis, las urbanizaciones cerradas son el contexto urbano de la ciudad cuyo estudio con datos censales presentó más problemas, debido a la combinatoria de escalas que asumen, respectivamente, el tipo de hábitat y las unidades geoestadísticas exteriores, y a la limitación del indicador de nivel socioeconómico para dar cuenta de niveles altos en la periferia no alcanzada por servicios básicos.

A partir de la información censal, se pudo saber que la población en urbanizaciones cerradas en 2010 no llegaría a los 150 mil habitantes. Este valor es consistente con los casi 156 mil habitantes que se pueden deducir al multiplicar las 43,805 parcelas edificadas según los registros de la Provincia de Buenos Aires para el año 2012-2013 (urBAsig, 2017) por el tamaño medio que tienen los hogares de este tipo de hábitat según el censo de población de 2010. Además, se confirmó que, con unos 650 habitantes por kilómetro cuadrado, es el entorno habitacional menos denso (dada la amplitud de los terrenos, la gran cantidad de espacios verdes de esparcimiento y el hecho de que se trata de un tipo de hábitat muy dinámico en la actualidad, con barrios en proceso de desarrollo o ampliación, cuyos lotes no se encuentran edificados y poblados en su totalidad).

Los conjuntos habitacionales de vivienda social, se presentan en polígonos aún más pequeños que las urbanizaciones populares de origen informal y las urbanizaciones cerradas. Sin embargo, al estar localizados en el sur de la CABA y las primeras coronas de municipios que la rodean, donde las unidades geoestadísticas censales no son excesivamente grandes, su identificación y caracterización revistió problemas similares a los de las urbanizaciones informales y de menor magnitud que las urbanizaciones cerradas.

En 2010 residirían en ellos unas 565 mil personas, valor que, dada la escases de información, es difícil de contrastar con otras fuentes, pero que se presume por debajo de la cifra real debido al exigente criterio de clasificación de radios mixtos utilizado.

Por la dotación de servicios básicos y equipamiento de los hogares y por el nivel educativo de sus habitantes, estos barrios conforman estratos socio-espaciales fundamentalmente medio altos ( 21 por ciento) y medios ( 35 por ciento), y en menor medida bajos (30 por ciento). Es decir que se trata de conjuntos de viviendas desarrolladas con financiamiento público para brindar solución habitacional definitiva a sectores populares, pero no necesariamente estuvieron destinados a los hogares más desfavorecidos de la estructura social. En la actualidad constituyen entornos que pueden tener composición media o baja y que incluyen desde barrios promovidos por 
mutuales y sindicatos para trabajadores formales, hasta soluciones habitacionales para población relocalizada de villas o asentamientos informales.

Finalmente, el resto de la superficie de la aglomeración corresponde a la conurbación de la ciudad colonial y los antiguos cascos urbanos en base al fraccionamiento de parcelas rurales y la posterior venta y edificación de los lotes en apego a la normativa vigente. Es decir que más de tres cuartas partes de la superficie de la AGBA es casi íntegramente de autopromoción, en la medida que los hogares compraron terrenos y construyeron viviendas por sí mismos o mediante la contratación de obreros especializados y hasta profesionales para el diseño y la dirección de la obra, de acuerdo a sus posibilidades económicas. Ello dio lugar a entornos que tienen al loteo formal como denominador común, pero que pueden constituir estratos socio-espaciales muy distintos. En los fraccionamientos por loteo formal de nivel socioeconómico alto del centro y norte de la CABA, el eje de suburbanización compacta de las elites hacia el norte y las proximidades de los viejos cascos urbanos conurbados, residen unas 674 mil personas. Los fraccionamientos por loteo formal de nivel socioeconómico medio reúnen tres millones 371 mil personas y se comportan espacialmente como un área de transición hacia la periferia degradada, donde viven cinco millones 738 mil personas sin infraestructura urbana básica.

\section{REFLEXIONES FINALES}

El presente trabajo estuvo motivado por los promisorios resultados que arrojaron los estudios mexicanos y argentinos que se valen del concepto de tipos de hábitat (llamados en México "tipos de poblamiento") como vínculo entre el complejo proceso de poblamiento que dio lugar a la ciudad construida y las estructuras demográficas y condiciones de vida diversas que se pueden encontrar en su interior. En este sentido, los tipos de hábitat brindan la oportunidad de vincular de forma empírica la dimensión material y la dimensión social del espacio, e integrar aspectos de la realidad urbana usualmente abordados por separado e inclusive desde diferentes disciplinas.

El eje estuvo puesto en los desafíos metodológicos que condicionan el proceso de medición de forma integral: desde la trasposición de los conceptos teóricos en definiciones operacionales, hasta la identificación de las categorías en la cartografía censal y su estudio a partir de los datos de esa misma fuente. En base al caso de la Buenos Aires metropolitana, se ilustró un camino que puede ser sumamente arduo y prolongarse en el tiempo. Ello se debe, fundamentalmente, a que en la complejidad y multidimen- 
sionalidad del concepto a medir radican, a la vez, su gran potencial y los mayores desafíos para que el proceso de operacionalización llegue a buen puerto, dado que se requiere reunir fuentes de datos secundarios de tipo, calidad y características diversas, y ponerlas a punto para su adecuación a las definiciones y manipulación conjunta.

A grandes rasgos, lograr una distancia aceptable entre la definición teórica del concepto de tipos de hábitat y la definición operacional de sus categorías depende en buena medida de la disponibilidad de datos. Los casos de México y Buenos Aires pueden citarse como ejemplos de que es posible en las grandes metrópolis latinoamericanas - $\mathrm{O}$ al menos en las de los países de renta media con sistemas estadísticos más sólidos-.

En cambio, el estudio posterior de los tipos de hábitat mediante datos censales puede verse muy comprometido por el problema de la unidad espacial modificable. Los más afectados son los tipos de hábitat que se presentan en pequeños polígonos o que se localizan en la periferia de la ciudad, donde las unidades geoestadísticas censales tienen mayor superficie. En el caso de Buenos Aires, urbanizaciones informales y conjuntos habitacionales de vivienda social son ejemplos claros de la primera situación y urbanizaciones cerradas de la segunda. Según la literatura, las experiencias mexicanas tampoco estuvieron exentas de este escollo. En términos empíricos, el denominador común es la existencia de unidades geoestadísiticas censales que se superponen con más de un tipo de hábitat y no son funcionales para dar cuenta de ellos.

En el caso de Buenos Aires, ante este problema se aplicaron criterios de clasificación de las unidades geoestadísticas exigentes, en una labor meticulosa que involucró operaciones de superposición de capas con sistemas de información geográfica, ajuste de las unidades geoestadísticas, exploración de imágenes satelitales y consulta de los datos censales asociados. Como resultado, se obtuvo una clasificación de la ciudad por tipos de hábitat con relativa debilidad para dar cuenta del tamaño absoluto en superficie y población de cada uno de ellos (en especial, de aquellos que se presentan en pequeños polígonos); $\mathrm{y}$, a la vez, de solidez aceptable para dar cuenta de la heterogeneidad sociodemográfica relativa asociada al proceso de poblamiento y la forma de producción del espacio habitacional, lo cual quedó plasmado en los resultados obtenidos en la caracterización de los tipos de hábitat por nivel socioeconómico y necesidades básicas insatisfechas.

Lejos de concluir un camino, los resultados a los que se ha arribado constituyen una base metodológico-conceptual para continuar avanzando en el campo de estudio en el que se insertan. En el nivel más amplio, se 
han generado condiciones de replicabilidad del abordaje en otras ciudades de la región y fuera de ella. Esto es fundamental para allanar el camino de la conformación de un corpus que permita contrastar la hipótesis que subyace al concepto mismo de tipo de hábitat o tipo de poblamiento, según la cual existirían entornos urbanos cuya identidad sociodemográfica está atravesada por el proceso de poblamiento de la ciudad (desde sus momentos fundacionales hasta la actualidad) y, en particular, por el efecto de algunos atributos fundamentales, como las condiciones históricas de diferentes etapas del asentamiento de la población en el territorio, los actores que dinamizaron la urbanización y la condición de regularidad inicial de la tenencia de las viviendas.

En el nivel del caso de Buenos Aires, su clasificación en tipos de hábitat es un hito en los estudios de la estructura urbana de esta ciudad, que invita a pensar la metrópolis en su integridad, considerando a sus partes, pero sin perder de vista el todo. Además de utilizar la tipología como variable independiente en estudios de diversa índole, es posible abordar las problemáticas específicas de cada uno de esos entornos habitacionales con datos en la mano, tanto desde el ámbito académico como de la gestión. Y, finalmente, el trabajo sienta las bases para su rápida actualización con datos del próximo censo de población argentino a realizarse en el año 2022 y la inauguración de una serie de datos comparables en el tiempo sobre una de las principales metrópolis de América Latina.

\section{Agradecimientos}

Este artículo se inscribe en el proyecto I+D "Desigualdades microespaciales urbanas: un estudio de las condiciones sociohabitacionales en distintos tipos de hábitat de la Región Metropolitana de Buenos Aires" (32/375, Universidad Nacional Tres de Febrero, Argentina). Agradezco a Mercedes Di Virgilio, quien me introdujo en el estudio de los tipos de poblamiento, y la colaboración de Gonzalo Rodríguez, Nicolás Caloni, Juan Pablo del Río, Gastón Cirio y Gabriela Mera.

\section{REFERENCIAS BIBLIOGRÁFICAS}

Abba, A. P., 2008, "La contribución de Puerto Madero a la centralidad metropolitana de Buenos Aires: proyecto urbano y sistema de lugares centrales", en Centro- $h,(2)$, pp. 73-88.

Bekinschtein, E., Calcagno, L. y Risso Patrón, D. P., 2013, Programa de rehabilitación de los Conjuntos Habitacionales construidos por el Estado. Buenos Aires: SSDUyV, SCA, CPAU. 
Borsdorf, A., Hildalgo, R. y Vidal-Koppmann, S., 2016, "Social segregation and gated communities in Santiago de Chile and Buenos Aires. A comparison", en Habitat International, 54, pp. 18-27.

Bozzano, H., 2003, Atlas Metropolitano de Buenos Aires.

Buzai, G. D. y Marcos, M., 2012, "The social map of Greater Buenos Aires as empirical evidence of urban models", en Journal of Latin American Geography, 11(1), pp. 67-78.

Castells, M., 1977, La cuestión urbana. Mexico: Siglo XXI Editores.

Ciccolella, P. y Vecslir, L., 2012, "Dinámicas, morfologías y singularidades en la reestructuración metropolitana de Buenos Aires", en Revista Iberoamericana de Urbanismo, (8), pp. 23-41.

Connolly, P., 2005, Tipos de poblamiento en la Ciudad de México. Departamento de Sociología Área de Sociología Urbana, Universidad Autónoma metropolitana.

COPEVI, 1978, Estudio de Densidades Habitacionales y Revisión de la Zonificación Secundaria. Mexico: Unidad de Coordinación del Plan Director, Dirección General de Planeación, Departamento del Distrito Federal/Centro Operacional de Poblamiento y Vivienda.

Cravino, M. C., 2006, Las Villas de la Ciudad: Mercado e Informalidad Urbana. Los Polvorines: Universidad Nacional General Sarmiento.

Cravino, M. C., 2009, "La metamorfosis de la ciudad informal en el Área Metropolitana de Buenos Aires", en Revista Lider, 15(11), pp. 31-55.

Cravino, M. C., Del Río, J. P. y Duarte, J. I., 2010, “Los barrios informales del Área Metropolitana de Buenos Aires: evolución y crecimiento en las últimas décadas", en Ciudad y territorio: Estudios territoriales, (163), pp. 101-114.

Dadamia, R., 2019, “Asentamientos precarios en la Ciudad Autónoma de Buenos Aires”, en Población de Buenos Aires, 16(28), pp. 20-33.

Del Río, J. P., Duarte, J. I., Graham, M. I., y Varela, D. O., 2008, “Creación de una base de datos georreferenciada de un fenómano dinámico: las villas y asentamientos del AMBA", en en Cravino, M. C. (Cpomp.), Los mil barrios informales del Área Metropolitana de Buenos Aires. Aportes para la construcción de un observatorio del hábitat popular. Los Polvorines: Universidad Nacional de General Sarmiento, pp. 65-86.

DGEyC (s/f), Cartografia, disponible en https:/www.estadisticaciudad.gob.ar/ eyc/

Di Virgilio, M. M. D., Aramburu, F. y Chiara, C., 2017, "Los planes federales de vivienda en el área metropolitana de Buenos Aires", en URBANA: Revista Eletrônica do Centro Interdisciplinar de Estudos sobre a Cidade, 9(1), pp. 70-96.

Di Virgilio, M. M., Marcos, M. y Mera, G., 2016, "Heterogeneidades socio-habitacionales en la ciudad de Buenos Aires: indagaciones sobre la base de una tipología de entornos urbanos", en Cuaderno urbano, 20(20), pp. 0-0. 
Di Virgilio, M. M., Marcos, M. y Mera, G., 2015, "Las ciudades dentro de la ciudad: características sociodemográficas y habitacionales de la Ciudad de Buenos Aires según sus tipos de hábitat", en Población de Buenos Aires, 12(22), pp. $33-57$.

DPOUyT, 2007, Lineamientos Estratégicos para la Región Metropolitana de Buenos Aires. La Plata: Subsecretaría de Urbanismo y Vivienda, Ministerio de Infraestructura, Vivienda y Servicios Públicos, Gobierno de la Provincia de Buenos Aires.

Duhau, E. y Giglia, A., 2008, Las reglas del desorden: habitar la metrópoli. México: Siglo XXI.

Dunowicz, R. y Boselli, T., 2009, "Habitar en la vivienda social de Buenos Aires, 1905-2002”, en Borthagaray, J. M. (comp.) Habitar Buenos Aires: Las manzanas, las casas y los lotes. Buenos Aires: FADU-UBA.

Dunowicz, R. y Rey, E., 2000, 90 años de vivienda social en la ciudad de Buenos Aires. Buenos Aires: FADU-UBA.

Gabosi, M. J., Dattoli, J. y Pérez, I., 2011, "Relevamiento de barrios informales en el Aglomerado del Gran Buenos Aires y en la Provincia de Córdoba", en Revista CIS, 9(15), pp. 79-86.

Giddens, A., 1984, La constitución de la sociedad. Buenos Aires: Amorrortu.

Goicoechea, M. E., y Abba, A., 2020, “Geografías de la desigualdad en el nuevo milenio: Los mapas sociales de la Buenos Aires metropolitana", en Notas de Población, 110, pp. 213-242.

Groisman, F. y Suárez, A. L., 2009, "Residential segregation in Greater Buenos Aires", en Urban segregation and governance in the Americas. Roberts, B. R. y Wilson, R. H. Nueva York: Springer, pp. 39-54.

Harley, J. B., 2005, La nueva naturaleza de los mapas. Ensayos sobre la historia de la cartografía. México: Fondo de Cultura Económica.

Harvey, D., 1998, La condición de la posmodernidad. Buenos Aires: Amorrortu.

INDEC, 2010, Censo Nacional de Población, Hogares y Viviendas 2010. Instituto de la Vivienda de la Provincia de Buenos Aires, 2011, Registro de conjuntos habitacionales. Instituto de la Vivienda de la Provincia de Buenos Aires (IVBA).

IVBA, 2011, Registro de conjuntos habitacionales. Inédito. Instituto de la Vivienda de la Provincia de Buenos Aires.

Janoschka, M., 2002, "El nuevo modelo de la ciudad latinoamericana: fragmentación y privatización”, en EURE, 28(85), pp. 11-20.

Lefebvre, H., 1972, La revolución urbana. Madrid: Alianza Editorial.

Magadán, M. L., 2003, Buenos Aires, planeamiento urbano y patrimonio cultural. Especialización en Gestión del Patrimonio Cultural Integrado al Planeamiento Urbano de América Latina. Programa ITUC/AL. 
Marcos, M., 2015, "Estructura socioespacial de la Aglomeración Gran Buenos Aires", en Geo UERJ, (26), pp. 22-54.

Marcos, M., Mera, G. S. y Di Virgilio, M. M., 2015, "Contextos urbanos de la Ciudad de Buenos Aires: una propuesta de clasificación de la ciudad según tipos de hábitat", en Papeles de población, 21(84), pp. 161-196.

Mazzeo, V., Lago, M. E. y Wainer, L. E., 2008, "Hábitat y población: el caso de la población que vive en inquilinatos, hoteles, pensiones y casas tomadas de la Ciudad de Buenos Aires", en Población de Buenos Aires, 5(7).

Mera, G., Marcos, M. y Di Virgilio, M. M., 2015, "Migración internacional en la Ciudad de Buenos Aires: un análisis socioespacial de su distribución según tipos de hábitat", en Estudios demográficos y urbanos, 30(2), pp. 327-367.

Openshaw, S., 1977, “A Geographical Solution to Scale and Aggregation Problems in Region-Building, Partitioning and Spatial Modelling”, en Transactions of the Institute of British Geographers, 2(4), p. 459.

Orueta, F. D., Lourés, M. L., Rodríguez, C., y Devalle, V., 2003, “Ciudad, territorio y exclusión social. Las políticas de recualificación urbana en la ciudad de Buenos Aires", en Reis, (103), pp. 159-185.

Ostuni, F. et al., 2008, "Renovación urbana y sector inmobiliario: algunas reflexiones a partir de La Boca, Barracas y San Telmo", en Herzer, H. (ed.) Con el corazón mirando al sur. Transformaciones en el sur de la ciudad de Buenos Aires. Buenos Aires: Espacio editorial.

Pérez, E. G. y Fernández, J. S., 2014, “Gentrificación en centros urbanos: Aproximación comparada a las dinámicas de Madrid y Buenos Aires", en Quid 16. Revista del Área de Estudios Urbanos, 0(3), pp. 49-66-66.

Quiroga, C. y Casali, D., 2021, "Cómo es el plan que busca convertir al microcentro en una ciudad de 15 minutos", en La Nación, 8 de julio. Disponible en https:// www.lanacion.com.ar/propiedades/construccion-y-diseno/como-es-el-plan-quebusca-convertir-al-microcentro-en-una-ciudad-de-15-minutos-nid08072021/ consultado el 24/07/2021.

Rodríguez Vignoli, J., 2001, Segregación residencial socioeconómica: qué es?, cómo se mide?, qué está pasando?, importa? Santiago de Chile: CEPAL, Centro Latinoamericano y Caribeño de Demografía, División de Población (Serie Población y desarrollo, 16).

Rodríguez, G. M., 2016, “Desigualdades socioeconómicas y segregación residencial en dos décadas de signo político y económico opuesto: La aglomeración Gran Buenos Aires entre 1991 y 2010”, en Cuaderno urbano, (21).

Rodríguez, G. M. y Kozak, D. M., 2014, “Expansión física y demográfica y cambios en la densidad de la Aglomeración Gran Buenos Aires, 1750-2010", en Población de Buenos Aires, 11(20).

Roitman, S., 2003, "Barrios cerrados y segregación social urbana", en Scripta Nova, 7(146), pp. 57-72. 
Tipos de hábitat: definiciones y desafíos para su medición a partir del caso de la aglomeración Gran Buenos Aires / M. MARCOS

RPPVA, 2015, Registro Público Provincial de Villas y Asentamientos Precarios. Ministerio de Infraestructura y Servicios Públicos de la Provincia de Buenos Aires, Consultado el 6/05/2019. Disponible en http://190.188.234.6/registro/publico/

Torres, H. A., 1978, “El mapa social de Buenos Aires en 1943, 1947 y 1960. Buenos Aires y los modelos urbanos", en Desarrollo Económico, 18(70), pp. 163-204.

Thuillier, G., 2005, "El impacto socio-espacial de las urbanizaciones cerradas: El caso de la Región Metropolitana de Buenos Aires", en EURE 31(93), 5-20. Disponible en http://dx.doi.org/10.4067/S0250-71612005009300001

Torres, H. A., 1993, El mapa social de Buenos Aires (1940-1990). Buenos Aires: Universidad de Buenos Aires.

Torres, H. A., 2001, "Cambios socioterritoriales en Buenos Aires durante la década de 1990", en EURE, 27(80), pp. 33-56.

UrBAsig, 2017, Registro Provincial de Urbanizaciones Cerradas. Ministerio de Infraestructura y Servicios Públicos de la Provincia de Buenos Aires. Consultado el 6/05/2019. Disponible en http://www.urbasig.minfra.gba.gov.ar/urbasig/_

Vapñarsky, C. A., 1998, El concepto de localidad: definición, estudios de caso y fundamentos teórico-metodológicos. Buenos Aires: INDEC.

Vapñarsky, C. A., 2000, La aglomeración Gran Buenos Aires: expansión espacial y crecimiento demográfico entre 1869 y 1991. Buenos Aires: Eudeba.

Vergara Parra, A. B., 2018a, "Segregación socioterritorial en la Región Metropolitana de Buenos Aires: análisis espacial intraurbano, características y evolución reciente, 2001-2010”, en Notas de Población, (106), pp. 251-284.

Vergara Parra, A. B., 2018b, "Segregación socio-territorial en la Región Metropolitana Buenos Aires (RMBA): controversias y aportes en torno a la cuantificación de la población en villas de emergencia y asentamientos precarios. Período 20012010”, en Revista Iberoamericana de Urbanismo, (14), pp. 87-104.

Vidal-Koppmann, S., 2008, "Mutaciones metropolitanas: de la construcción de barrios cerrados a la creación de ciudades privadas: balance de una década de urbanización privada en la región metropolitana de Buenos Aires", en Scripta Nova, 12.

Wong, D., 2009, “The modifiable areal unit problem (MAUP)", en Fotheringham, A. S. and Rogerson, P. (eds) The SAGE handbook of spatial analysis. SAGE Publications, pp. 105-124.

\section{RESUMEN CURRICULAR DE LA AUTORA}

\section{Mariana Marcos}

Doctora en Ciencias Sociales (Universidad de Buenos Aires), Especialista en Demografía Social (Universidad Nacional de Luján) y Socióloga (Universidad de Buenos Aires). Se desempeña como investigadora del Consejo Nacional de Investigaciones Científicas y Técnicas (CONICET) en el 
Instituto de Investigaciones Gino Germani de la Universidad de Buenos Aires (Argentina) y como docente de la Universidad Nacional de Tres de Febrero. Investiga temas de demografía urbana y demografía residencial, tales procesos de poblamiento y de distribución y segregación espacial de la población urbana; proyección de hogares y demanda demográfica de viviendas; déficit habitacional; creación y disolución de hogares y escenarios urbanos de planificación derivados. Actualmente, su investigación básica se centra en los determinantes demográficos de las necesidades de vivienda presentes y futuras en Argentina, incluidas las perspectivas comparativas internacionales de nivel metropolitano y nacional.

Dirección electrónica: mmarcos@conicet.gov.ar

Registro ORCID: https://orcid.org/0000-0002-2005-3076

Artículo recibido el 14 de junio de 2019 y aprobado el 26 de mayo de 2021. 